Article

\title{
Spatial and Temporal Distribution of Chemically Characterized Microplastics within the Protected Area of Pelagos Sanctuary (NW Mediterranean Sea): Focus on Natural and Urban Beaches
}

\author{
Silvia Merlino ${ }^{1, *(\mathbb{D}}$, Marina Locritani ${ }^{2}{ }^{(\mathbb{D}}$, Gabriele Bernardi $^{3}$, Carlotta Como ${ }^{4}$, \\ Stefano Legnaioli ${ }^{5}$, Vincenzo Palleschi ${ }^{5}$ (D) and Marinella Abbate ${ }^{6}$ \\ 1 Istituto di Scienze Marine del Consiglio Nazionale delle Ricerche, ISMAR-CNR, 19032 Lerici (SP), Italy \\ 2 Istituto Nazionale di Geofisica e Vulcanologia, Via di Vigna Murata 605, 00143 Roma, Italy; \\ marina.locritani@ingv.it \\ 3 Department of Earth Sciences, University of Pisa, Via S. Maria, 52, 56126 Pisa, Italy; \\ gabrielebernardi@gmail.com \\ 4 Department of Life Sciences and Systems Biology, University of Torino, Via Accademia Albertina, 13, \\ 10123 Torino TO, Italy; carlottacomo@yahoo.it \\ 5 Istituto di Chimica dei Composti OrganoMetallici del Consiglio Nazionale delle Ricerche, ICCOM-CNR, \\ Via Moruzzi 1, 56124 Pisa, Italy; stefano.legnaioli@pi.iccom.cnr.it (S.L.); vincenzo.palleschi@cnr.it (V.P.) \\ 6 ENEA-Agenzia nazionale per le nuove tecnologie, l'energia e lo sviluppo economico sostenibile, \\ Centro Ricerche Ambiente Marino di S. Teresa, Pozzuolo di Lerici, Via S. Teresa, 19032 Lerici SP, Italy; \\ marinella.abbate@enea.it \\ * Correspondence: silvia.merlino@sp.ismar.cnr.it
}

Received: 24 October 2020; Accepted: 25 November 2020; Published: 2 December 2020

\begin{abstract}
Data on the abundance and distribution of Anthropogenic Marine Debris (AMD) on the coastal areas of the northern Tyrrhenian coast are still scarce. The objective of this study is to characterize, in terms of size, color, morphology and polymeric nature, the Large Microplastics (LMPs), i.e., plastic objects within 1 and $5 \mathrm{~mm}$, sampled on three beaches located within the coastal macro-area of the Pelagos Sanctuary, an international protected zone in the north-western Mediterranean. The beaches have similar morphological characteristics but different degrees of urbanization. LMPs were sampled seasonally for one year. The polymeric nature of a representative subsample of the collected LMPs was investigated using a portable Raman instrument, to assess the feasibility of in situ characterization. In this study, 26,486 items were sorted by typology (Expanded Polystyrene-EPS, fragments, and resin pellets), size, and for fragments and resin pellets, also by color and chemical nature. Statistical data on the quantity, density, type, spatial distribution, and seasonality of the sampled LMPs are presented. Differences in LMP abundance and composition were detected among sites. A seasonality trend emerges from our statistical analysis, depending on both LMP typology and urbanization degrees of the beaches. Our data do not show the existence of a relationship between the size of the investigated MPs and their color, while they suggest that the type of polymer influences the degree of fragmentation. This underlines the need to further investigate the mechanisms leading to the production and dispersion of MPs in coastal areas, taking into account both the urbanization of the beach, and therefore the possible sources of input, and the different types of MPs. Finally, a Raman portable instrument proved to be a valuable aid in performing in situ polymeric characterization of LMPs.
\end{abstract}

Keywords: microplastics; beach monitoring; Marine Protected Areas; polymeric characterization; Raman spectroscopy; arine litter; AMD; Anthropogenic Marine Debris; Mediterranean shores 


\section{Introduction}

Among the emerging problems affecting coastal areas (erosion, loss of biodiversity, etc.), the accumulation of Anthropogenic Marine Debris (AMDs), also called Marine Litter (ML), has received increasing attention in recent decades [1]. Studies have focused in particular on ML accumulation in the open sea [2-4], and in coastal areas [5,6], but also in deep water sediment [7-9], in polar areas [10,11], and in freshwater systems [12-15]. Most of these works confirm that the percentage of "plastics" (including all artificial polymeric types) among the different categories of ML is very high, representing between $61 \%$ and $87 \%$ of AMDs $[16,17]$. The persistence of plastic materials and their slow degradation in the environment allows them to enter and accumulate in aquatic ecosystems, with possible harmful effects for the biota. Differences in the size of plastic pieces can lead to different effects; the proposed classification of Microplastics (MPs) into size classes takes this fact into account. The term Macroplastic generally refers to relatively large plastic objects $(2.5 \mathrm{~cm}-1 \mathrm{~m})$, i.e., artefacts still recognizable, such as bottles, containers, toys and buoys. Particles larger than $5 \mathrm{~mm}$ but smaller than $2.5 \mathrm{~cm}$ are defined Mesoplastic. Although the term MP is often used generically to refer to any small piece of plastic, and there is no universally agreed nomenclature [18-21], it is common to limit this term to particles less than $5 \mathrm{~mm}$ in diameter $[20,22,23]$. Several proposed classifications are based on different methodologies which have been adopted to collect and sort the material according to size, thus dividing them into small (0.1-1 mm) and large (1-5 mm) MPs [21]. Regarding the origin of MPs, they are known as "secondary" (e.g., fragments) when they result from the breakage of larger plastics [24-26], and as "primary" when they are released into the aquatic ecosystem due to direct losses, during transfer and transport to/from industries [20]. This second category includes microbeads (tiny microspheres used in cosmetics and other detergents, and nanoparticles used in industrial processes) and resin pellets, also called nurdles, a raw material used in molding and packaging to produce all kinds of plastic articles used in modern society $[18,27,28]$. The latter generally have a diameter of about $2-5 \mathrm{~mm}$ [29], so they fall into the category of LMPs. Considering that objects, especially plastic ones, left on the beach for months/years are subject to photo-degradation at a higher speed than if they were at sea [24,25], their fragmentation can lead to the production of very small plastic pieces. These, mixed with the substrate of the beach, can produce a flow of particles that spills into the sea, adding to those directly released by rivers [30,31]. It is therefore important, in line with the protocol and standard monitoring strategies [32-34] to collect information on the spatial and temporal distribution of marine waste on beaches, to identify the areas of greatest accumulation, quantify the abundance and type of materials, and possibly trace their origin and the contribution of different possible sources (rivers, tourism, etc.). Particularly at risk are the Marine Protected Areas (MPAs) located in or near densely populated and industrialized areas, as these suffer from a strong influx of AMDs which are difficult to remove, due to both the intrinsic difficulty of reaching these areas (often isolated or not served by roads or structures) and regulations which limit human intervention. ML monitoring on beaches should, therefore, consider the presence of parks and protected areas, as well as the seasonality, urbanization, and morphological characteristics of the coast.

In the Mediterranean, a semi-closed basin in which the phenomenon of waste accumulation is accentuated [35], increasing efforts have been made to detect the presence and determine the possible sources of AMDs in the open sea, the seabed and coastal areas [4,5,36-69]. In this context, the area of the upper Tyrrhenian Sea (north-western Mediterranean) and the neighboring Ligurian Sea are very sensitive to this type of pollution [70-72], especially as they host the Pelagos Sanctuary [73]. Cozar et al. [56] estimated the concentration of ML in the Mediterranean Sea basin, in terms of surface weight. The reported data showed that there was a fairly large range of values (from 22 to $1934 \mathrm{~g} / \mathrm{km}^{2}$ ), but noted that the area of the north-western Tyrrhenian Sea presented the greatest abundance. The latest studies that have focused on the floating ML in the Mediterranean, and in particular, in the waters surrounding the Italian peninsula, confirmed this [54,61,74]. The coasts included in these marine areas within the Pelagos Sanctuary are of extreme environmental importance, as they are rich in parks and MPAs located both near urban areas and in places that are not easily accessible and far from sources of direct pollution. Previous surveys of beach macrowaste carried out within the Pelagos 
Sanctuary, in a particular macro-area that includes that of our current survey, found that natural sites, and especially protected areas close to river mouths and/or located in places that are not easily accessible, showed a higher density than other areas [68,69]. As these beaches suffer from a lack of constant cleaning to remove accumulated debris including plastics, it is very plausible that these materials will degrade and fragment. These areas could then become a place of accumulation of meso- and micro- plastics. Despite the relative abundance of recent monitoring dedicated to beached marine waste in the Mediterranean area, few such programs concern the Italian coasts overlooking the Tyrrhenian part of this sea $[5,53,68,69]$, and none has dealt with MPs.

The objective of this study is to characterize, in terms of size, color, morphology, and polymeric nature, the LMPs sampled on three beaches (with different degrees of urbanization) in the North Tyrrhenian area. Furthermore, it is intended to quantify the accumulation of MPs on the selected beaches and study the differences in their spatial and temporal distribution, considering one year (four seasons) of sampling and three different areas within each beach. The correlation between MP densities and the different degrees of urbanization of the selected areas will be explored. Our selected area is part of the Pelagos Sanctuary, frequented for breeding and foraging by different species of cetaceans (striped dolphins or sperm whales are quite common). They can be damaged by the increasing amounts of plastic and AMDs from both land and sea; among these, mistycetes, which are filter-feeding mammals, are considered particularly at risk due to marine pollution in the form of MPs [70-72]. Finally, we evaluated the potential role and effectiveness of portable Raman spectroscopy for the direct in situ characterization of MP fragments. This technique, widely used $[51,75,76]$ in the study of polymeric materials (and not), is a nondestructive technique which provides data in a short time, and can be used on samples without any preparation. The most common techniques used to confirm the nature of MP samples are Infrared and Raman spectroscopies, which are complementary techniques, because molecular vibrations which are Raman inactive can be FTIR active and vice versa. However, Raman can achieve better spatial resolution, and furthermore, recent technological progress provide compact and reliable systems for in situ analyses that are appropriate for this kind of application.

\section{Materials and Methods}

\subsection{Study Area and Sampling Sites}

The selected area is a stretch of northern Tyrrhenian coast that includes two Tuscan provinces (Pisa and Lucca) and three municipalities (Pisa, Vecchiano and Viareggio). The choice of the sites was based on a report by Lippiatt et al. [77], taking into account factors such as the type of beach, the inclusion of areas near the river outlets and at least one protected area of type A (high degree of protection and prohibition of nautical activities, D. M. 979/1982 and D.M. 394/1991), in order to compare the results obtained in that site, in terms of the average density and type of predominant particles, with those of beaches with different tourist management approaches and cleaning frequencies. In this framework, three beaches (sampling sites) were identified within the area selected for the monitoring program (Figure 1): San Rossore (SR), Marina di Vecchiano (MV) and Viareggio (V). The sampling sites had the same type of substrate (soft sand of similar granulometry), the same conformation (linear beach with low slope and backdune environment), orientation (south-west) and wind exposure to prevailing south-west or north-east winds. 


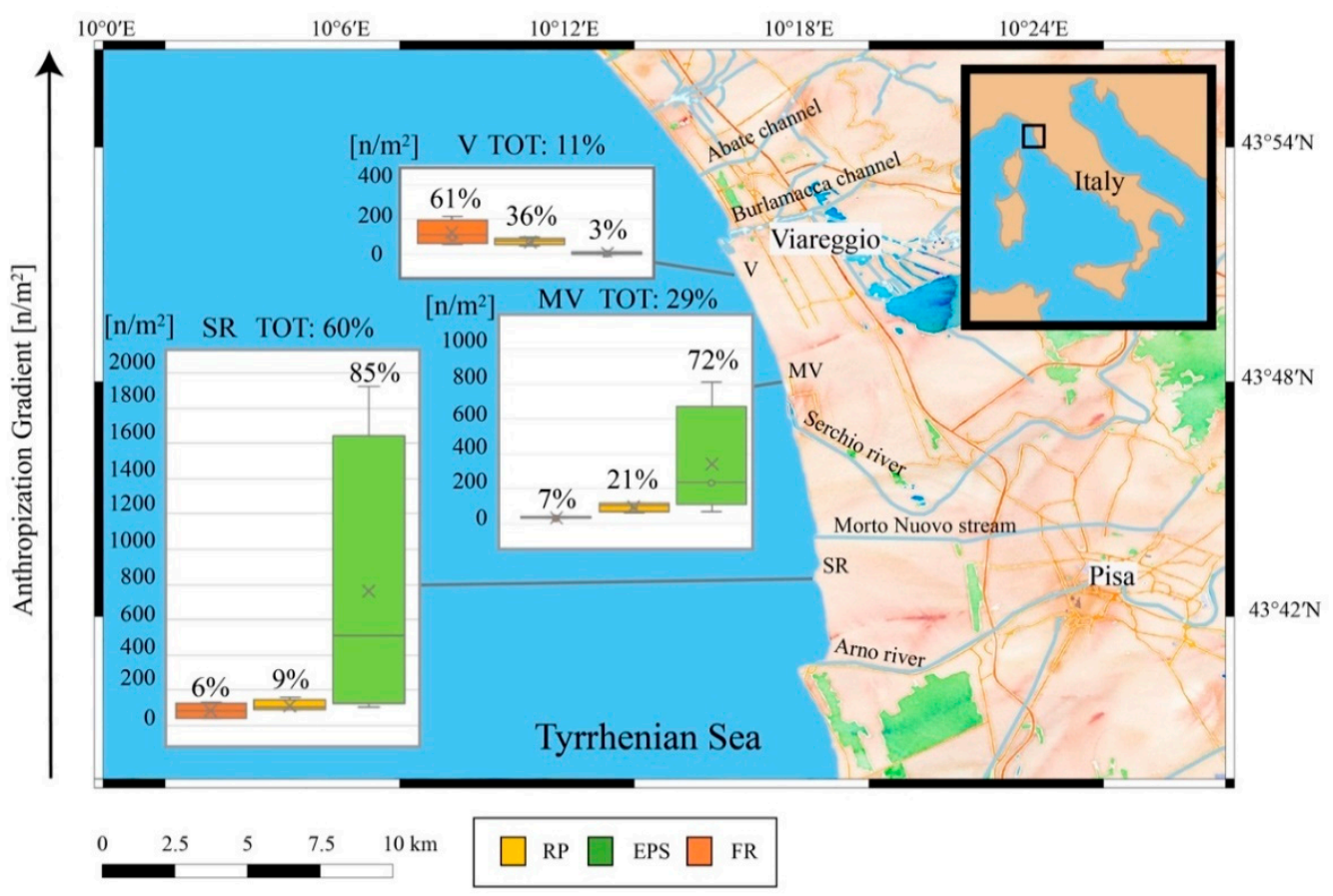

Figure 1. Geographical location of the three sampling sites, and distribution of the density of MPs sampled in the three sites (SR, MV and V). The anthropization gradients grow from the SR to the V site, and in geographical terms from south to the north. The $\mathrm{x}$ in the boxplot represent the mean values, the continuous lines the median values, the limits of the "boxes" the 75th and 25th percentile and the whiskers the maximum and minimum limit. In the SR site for the EPS fraction there is a high variability of the distribution (InterQuartile Range $=1254.68$ ) as well as in the MV site (InterQuartile Range $=194.68$ ). Image made using Stamen Watercolor/OSM base map in Qgis 2.18.2.

They are located a short distance from important river mouths (Arno and Serchio), which are potential sources and/or ML inputs. The sea currents in this area have a prevailing northward flow. Due to their different proximity to urban areas and the different types of tourism management implemented, the beaches studied were classified according to the system proposed by Ariza et al. [44] (Urban (U) beaches are located in residential and tourist areas that are cleaned on a regular basis, especially during tourist season, and as public service; Urbanized $(\mathrm{Uz})$ beaches are close to urban centers and may be visited by tourists but with a lower human presence compared to the previous category, and with fewer regular cleaning activities; Natural $(\mathrm{Na})$ beaches exhibit low levels of human impact, mostly isolated or located in MPAs, in many cases in the most restricted subareas, e.g., zones with a high degree of protection and prohibition of boating activities. Cleaning activities are usually not performed, but may be carried out under exceptional circumstances, e.g., during focused awareness campaigns by NGOs and volunteers. These beaches mostly receive AMD as transported by marine currents, rivers, waves, and wind. In detail: SR is a "natural-Na" beach, within the Migliarino, Massacciuccoli and San Rossore Park Protected Marine Area (SRPRK), with a dune cordon parallel to the coastline, marking the boundary of the coast (Figure S2, Supplementary Material). It is located $5 \mathrm{~km}$ from the mouth of the Arno River ( $\left.43^{\circ} 40^{\prime} 47.408^{\prime \prime}, \mathrm{E} 10^{\circ} 16^{\prime} 40.466^{\prime \prime}\right)$. MV, just north of the

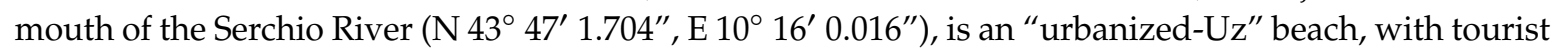
presence only in the summer months and without bathing facilities. V, the northernmost of the three sites (10 km north of the river Serchio), is an "urban- $U$ " beach, located near an inhabited center and close to accommodation facilities which are active not only during the summer, but also outside the tourist season.

Differences in tourist management and planning of beach use have also been considered, taking in account the period, frequency, and method of cleaning actions (Table 1). 
Table 1. Selected characteristics of the sites: width of the beach (distance sea-dune) (m); proximity to the river mouth $(\mathrm{Km})$; distance from the nearest town $(\mathrm{km})$; level of anthropization $(\mathrm{U}=\mathrm{Urban}$, $\mathrm{Uz}=$ Urbanized, $\mathrm{Na}=$ Natural); type of cleaning: A absent, MAN manual, MIXED mechanized/manual. Images (polygons) and the relative GPS coordinates identifying the selected stretch of beach in each site are reported in Figure S2, Supplementary Material.

\begin{tabular}{ccccccc}
\hline $\begin{array}{c}\text { Site Name } \\
\text { (Acronym) }\end{array}$ & $\begin{array}{c}\text { Total Width } \\
(\mathbf{m})\end{array}$ & $\begin{array}{c}\text { Proximity to } \\
\text { the River } \\
\text { Mouth } \mathbf{( k m )}\end{array}$ & $\begin{array}{c}\text { Distance from } \\
\text { the Nearest } \\
\text { Town } \mathbf{( k m )}\end{array}$ & Class & $\begin{array}{c}\text { Cleaning } \\
\text { Actions } \\
\text { Period }\end{array}$ & $\begin{array}{c}\text { Cleaning } \\
\text { Action Way }\end{array}$ \\
\hline $\begin{array}{c}\text { San Rossore } \\
\text { (SR) }\end{array}$ & 30 & 5 & 6.2 & $\mathrm{Na}$ & never & $\mathrm{A}$ \\
\hline $\begin{array}{c}\text { Marina di } \\
\text { Vecchiano } \\
(\mathrm{MV})\end{array}$ & 50 & 0 & 4.3 & $\mathrm{Uz}$ & $\begin{array}{c}\text { Late spring } \\
\text { /summer }\end{array}$ & $\begin{array}{c}\text { MAN } \\
\text { MIXED }\end{array}$ \\
\hline $\begin{array}{c}\text { Viareggio } \\
(\mathrm{V})\end{array}$ & 60 & 10 & 0 & $\mathrm{U}$ & Every season & MIXED \\
\hline
\end{tabular}

\subsection{Monitoring Program and Microplastic Sampling Design}

Sampling campaigns took place during the four seasons, with two temporal replicas for each season (except for the winter, due to bad weather), starting on 24 July 2016 and ending on 21 June 2017. The survey was carried out following the protocol recommended by the Marine Strategy Framework Directives $[33,78,79]$. Samples were collected from the three chosen beaches, in order to study the spatial and temporal distribution of MPs and characterize them in terms of dimension, color, polymeric types, and physical aspect. The sampling area for each site was the afitoic (i.e., a beach area free of wetlands, and therefore, of vegetation.) backshore of a stretch of a sandy beach, defined by a 100-m-long transept parallel to the shoreline, whose depth goes from what we call the "first accumulation line" of the material to the line of the dunes. This "first accumulation line" is the first zone close to the sea where it is possible to collect MP, as the very first strip of sand after the shoreline is generally wet and cannot be sampled with sieves. Measurements of the length and depth were taken for each beach with a tape measure, and the GPS coordinates relative to the starting and ending point were recorded (Table 1 and Figure S1 in Supplementary Material). As beaches are dynamic systems with constantly changing conditions, any sampling of MPs should take into account that the shoreline and accumulation line are very variable over relatively short periods of time. In this specific case, in the Mediterranean Sea and in the studied Area, given the weakness of tidal phenomena and their minimal influence on the extensions of the beaches, the foreshore is very small, and there is no significant variation, even inter-seasonally. Either way, we took into account the maximum extent of the tide in this area by choosing points of the beach starting at the limit of the "swash zone" (zone of the wave run-up). These considerations, and the precautions taken in the choice of area, proved to be good, also with regard to the state of the sea during the different seasons. In fact, despite several storm surges, and even a flood of the Arno River during the autumn, neither the extension nor the slope of the beach underwent substantial changes. This was further confirmed by what emerged from ML monitoring conducted later, in the same stretch of beach, with the help of Unmanned Aerial Vehicle, UAVs [80].

The sampling design included three fixed factors (Site, Season and Zone) plus three random replicas (sampling station) for each Zone. The "Zone" factor identified three transects parallel to shoreline and with a distance from $4 \mathrm{~m}$ (for SR) to $25 \mathrm{~m}$ (for V) between them, depending on beach size and characteristics. The transects were the sea area (Se) close to the shoreline, the intermediate area (I) representing the ordinary berm and the dune area (D). This factor was deliberately introduced in this work to study possible differences in the accumulation of MPs as a function of the distance from the shoreline (Figure S1 in Supplementary Material).

Previous studies have observed that over half of the total plastic fragments recovered from beaches is in the top $5 \mathrm{~cm}$ of sediment, and nearly $95 \%$ is found in the top $15 \mathrm{~cm}$ [81]. For the sake of simplicity, 
we decided, following the prescriptions of the MSFD [33], to consider only the surface layer $(5 \mathrm{~cm}$ depth) as a sufficiently representative sample. A first coarse "sorting" phase was done directly on the beach, eliminating shells, pebbles and pieces of wood, and the remaining items were placed in an aluminum box, labeled, and transferred to the laboratory.

\subsection{Sample Analysis}

Once at the laboratory, after a cleaning with distilled water, the samples were dried at room temperature for at least $24 \mathrm{~h}$. MP items were separated by natural objects with metal tweezers prior to the density separation procedure. Density sorting was performed by flotation, i.e. a "density sorting" [27,75,82], with the addition of a saturated solution of $\mathrm{NaCl}$ at $35 \%, \rho=1034 \mathrm{~g} / \mathrm{cm}^{3}$ (The subgroup of the framework directive on marine environment strategies (MSFD, [33]) recommended the use of $\mathrm{NaCl}$ for the separation of MP by density flotation), as it is a cheap and environment-friendly salt. However, the use of a saturated solution of $\mathrm{NaCl}\left(\rho=1.2 \mathrm{~g} / \mathrm{cm}^{3}\right)$ in tap water can lead to underestimating the content of microplastics in sediments because the density of the solution is too low to allow the flotation of all polymers, mainly those containing additives [82] while a saturated solution of $\mathrm{NaI}\left(\rho=1.6 \mathrm{~g} \mathrm{~cm}^{3}\right)$ is sufficient to separate the polymers containing additives.) Floating particles (including natural residual items and visible MP particles) were collected from the surface of the saturated solution using metal tweezers, saved in glass Petri dishes, and dried in a muffle at $40^{\circ} \mathrm{C}$. This procedure was repeated until no visible particles were floating, and particles were recovered in Whatman ${ }^{\circledR} \mathrm{GF} / \mathrm{C}$ filters $(\sim 1.2 \mu \mathrm{m}$ pore; $\varnothing=47 \mathrm{~mm})$. Filters were then observed under a Nikon ${ }^{\circledR}$ AZ100 stereomicroscope, to recover MPs with smaller dimensions. This additional "visual sorting" was necessary to reduce the margin of error caused by possible changes in polymer density (and, therefore, in their buoyancy) due to the additives incorporated in the production process [82], biofouling or degradation due to aging [19]. All possible precautions were taken to avoid contamination of the samples (for example, use of $100 \%$ cotton lab-coats).

All collected items were counted, measured and then separated into size classes (1-2, 2-3, 3-4, $4-5 \mathrm{~mm}$ ), and into three macrocategories (Figure 2), i.e., resin pellets (RP), fragments (FR) and expanded polystyrene (EPS), placing them in different decontaminated aluminum containers. Each FR piece was characterized also by its color (White Old $=$ WH-OL, White-Glossy $=$ WH-GL, Transparent $=$ TR, Amber $=\mathrm{AM}$, Yellow $=$ YE, Green $=\mathrm{GR}$, Black $=\mathrm{BK}, \mathrm{Gray}=\mathrm{GY}$, Red $=\mathrm{RE}, \mathrm{Blue}=\mathrm{BL}$, Other colors $=\mathrm{OT}$ ), as well as each RP piece (Transparent-Glossy $=$ TR-GL; white $=\mathrm{WH}$; amber $=\mathrm{AM}$; colored $=\mathrm{COL}$ ), as also shown in the Figures S3 and S4 in Supplementary Material. Differences in color classification between FR and RP were due to the different nature of the two MP types, respectively secondary MPs proceeding from macro objects containing additives and colorants added during production, and primary MPs mostly constituted by virgin polymers without additives, with a typically glossy and semitransparent appearance when they are new, but opaque white or with "amber" shades, more or less dark, when they are older.

A representative subsample of the total number of recovered particles (about $1 / 4$ ) were analyzed to identify the plastic polymer composition of the material. Fragments were analyzed at the Applied and Laser Spectroscopy Laboratory of the Institute of Organometallic Compounds of CNR, Pisa, Italy by using an i-Raman Plus spectrometer by BWTek $@$, coupled to a microscope and a portable PC. The measurements were done accumulating three spectra with acquisition time of $30 \mathrm{~s}$. The power of the laser beam (@785 nm) was about $350 \mathrm{~mW}$. The spectra were acquired with a resolution of $1 \mathrm{~cm}^{-1}$ in a range from $200 \mathrm{~cm}^{-1}$ to $3200 \mathrm{~cm}^{-1}$. The i-Raman Plus is a portable instrument which was used to evaluate its effectiveness for future in situ characterizations of MPs. Despite a lower resolution associated with this kind of compact instrumentation, almost all the collected samples were identified by comparing the acquired spectrum with a database of spectra of the main polymers. Only in a few cases (about 3\% of items), the Raman spectra could not be interpreted due to high fluorescence, because of the unevenness of the sample surface, or color and oxidation of the surface layer. The spectra of the samples collected on the beaches presented a greater complexity (number of 
peaks) than the standard reference samples. This finding was confirmed by results in the literature, and may be attributed to the presence of additives, dyes and inorganic substances (titanium oxides, iron etc.) incorporated in the matrix, as also identified by the Raman system.

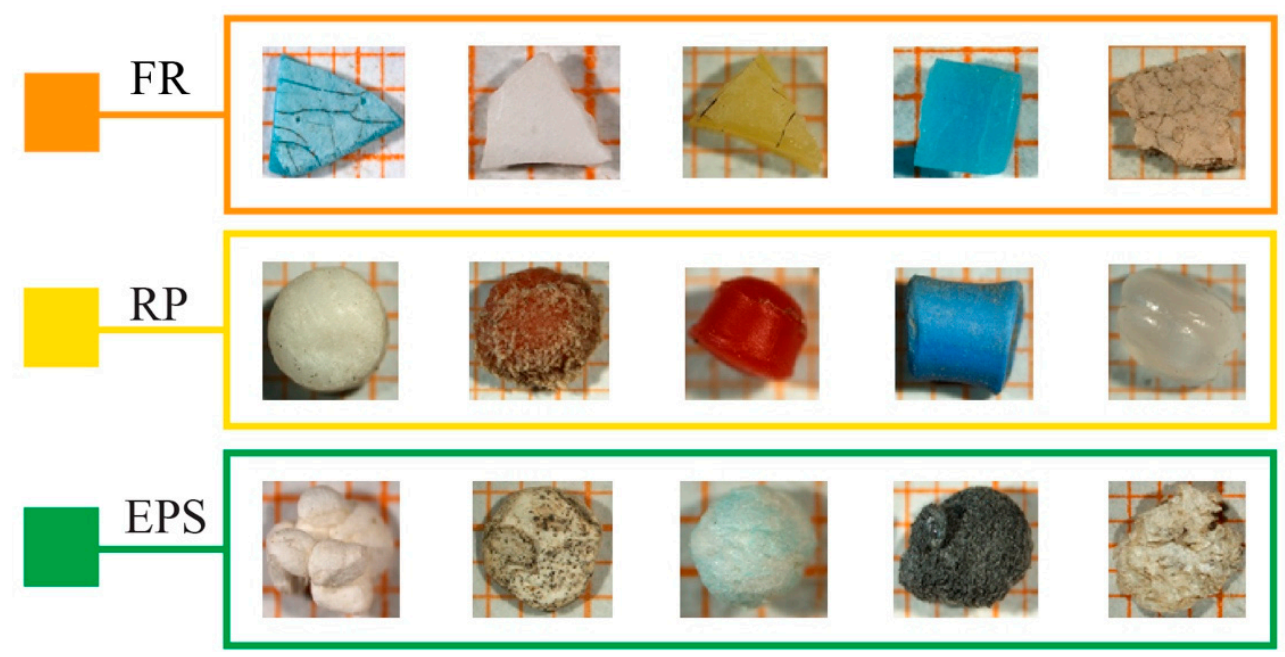

Figure 2. Physical appearance and color of some microplastics among those sampled, divided into the three types considered. Legend: FR = fragments, $\mathrm{RP}=$ resin pellets, EPS = expanded polystyrene.

The RP items were analyzed using a ATR PerkinElmer GX spectroscope, equipped with PIKE MIRacle ${ }^{\mathrm{TM}}$ ATR, with germanium crystal and $45^{\circ}$ angle incidence of radiation on ATR crystal (background acquisition and analysis with 8 scans, wavelengths $4000-650 \mathrm{~cm}^{-1}$ ), at the Spectroscopy Laboratory of Department of Chemistry and Industrial Chemistry, Pisa University.

The identification of each sample was made by comparing the spectrum acquired by the instrument with a database of spectra of the main polymers available in the literature and by comparison with standard libraries [75,76,83-101]. It must be noted that also in this case, the spectra of the samples collected on the beaches were more complex (larger number of peaks) than those of the standard reference samples, due to the presence of possible additives, dyes or inorganic substances (titanium oxides, iron, etc.) incorporated into the matrix, or due to aging.

\subsection{Data Analysis}

As a sampling variable, we used both the number of particles collected (for color and dimensional classification) and the density expressed in number of particles per square meter (for spatial and zonal distribution), following previous studies and also the MSFD. The mean density value for each site was obtained considering all time replicas of the same beach, as well as the seasonal mean density was obtained considering replicas within the same season for each beach. For each season, two replicates were made, except in winter, when only one was possible. The analysis of the mean zonal density of MPs was carried out by counting the debris separately collected in each of the three beach areas. The obtained variables are total density, seasonal density, and zonal density for each of the three sites. The normality of the distribution of variables was checked by the Shapiro-Wilk test. For the study of spatial distribution and the temporal distribution of MPs, comparisons by site, sampling area and season were conducted considering the individual samples (out of a total of 189 samples), and were made using the nonparametric Kruskal-Wallis test for non-normal distribution variables. The significance level for all analysis was set at $95 \%(p=0.05)$. The data are reported as mean \pm SD and median (interquartile range - IQR). All calculations were performed using StataSE/15 (Stata Corp., College Station, TX, USA). Results of color and dimensional classification of collected MP are expressed by the total number of sampled objects for each site and for each category (color or size), averaged over the time replicas made for each season (Tables S1-S3 in Supplementary Material). 


\section{Results}

\subsection{MP Classification}

During monitoring, 26,486 MP with an average size between $1 \mathrm{~mm}$ and $5 \mathrm{~mm}$ were collected from the three beaches (16,165 in SR, 7621 in MV and 2700 in V), through 189 samplings. The particles were divided into three classes: expanded polystyrene (EPS, for a total of 18,274 items, 69\%), fragments (FR, for a total of 4767 items, 18\%) and pellets (RP, for a total of 3443 items, 13\%).

\subsection{Spatial and Temporal MP Distribution}

The data collected allowed us to obtain local and seasonal density values for MPs, and so to examine in detail the spatial and temporal distribution of them in the three sampled sites. The SR site presented the highest total (the three MP typologies combined) mean density $\left(958.7 \pm 792\right.$ items $/ \mathrm{m}^{2}$; $\mathrm{n}=18)$, followed by the MV site $\left(471.3 \pm 333\right.$ items $\left./ \mathrm{m}^{2} ; \mathrm{n}=18\right)$ and the V site $\left(175.4 \pm 42\right.$ items $/ \mathrm{m}^{2}$; $\mathrm{n}=18$ ). A mean value of $535.13 \pm 389 \mathrm{MP}$ particles per square meter was calculated for the entire sampling. In Table S1 (Supplementary Material), the density values (number of items/ $\mathrm{m}^{2}$ ) obtained for each site and season are reported, calculated considering the temporal and spatial replicas.

The density values recorded at the SR and MV sites were characterized by a high dispersion, mainly due to the EPS typology (Figure 1). The three categories of MPs monitored (FR, RP and EPS) had different origins (primary in the case of RP, secondary in the case of FR and EPS) and also different dispersion patterns, due both to localized anthropogenic pollution (mainly for FR) and to contributions from the sea and rivers (for EPS and, in particular, for RP), as reported in Table 2. For this reason, the spatial distributions of the three distinct categories of MPs were analyzed separately.

Table 2. The Table shows the identified categories of MPs, their origin, and the way they are dispersed in the environment.

\begin{tabular}{ccc}
\hline MP Type & Origin & Dispersion Modes \\
\hline FR & Secondary & By river and sea, and particularly from localized anthropogenic pollution \\
\hline RP & Primary & Dispersion by river and sea \\
\hline EPS & Secondary & Especially by river and sea, and also from localized anthropogenic pollution \\
\hline
\end{tabular}

The boxplot graphs in Figure 1 summarizes the obtained results. The SR site showed a very high mean density value for the EPS fraction (SR $760 \pm 836$ items $/ \mathrm{m}^{2}$ ), followed by the MV site $\left(340 \pm 323\right.$ items $\left./ \mathrm{m}^{2}\right)$, and by the very low value of $\mathrm{V}$ site $\left(6.5 \pm 4\right.$ items $\left./ \mathrm{m}^{2}\right)$. In contrast, the SR mean density value for the fraction of RP (SR $114 \pm 99$ items $/ \mathrm{m}^{2}$ ) was comparable with those of the other sites (MV $97 \pm 98$ items $/ \mathrm{m}^{2} ; \mathrm{V} 72 \pm 58$ items $/ \mathrm{m}^{2}$ ). The fraction of FR (SR $84 \pm 67$ items $/ \mathrm{m}^{2}$; MV $34 \pm 32$ items $/ \mathrm{m}^{2} ; \mathrm{V} 95 \pm 71$ items $/ \mathrm{m}^{2}$ ) showed a maximum value in $\mathrm{V}$, with an opposite trend with respect to the other two MP categories. In both SR and MV, the EPS fraction showed high variability due to significant differences between the individual samples. The data are reported in Table S2, Supplementary Material).

The temporal trend of the density values over the four different seasons was also studied. A greater seasonal variability was evidenced in SR and MV with respect to V (Figure 3). In the two first sites, the highest MP density values were found in autumn, while in V, the highest density value was in winter, even if it was very close to the autumn values. Interestingly, in summer, the SR site showed much higher density values of MP compared to MV and V sites.

In order to verify the reliability of the seasonal and spatial differences observed, a statistical analysis was carried out to compare the density of the different MP categories, separately, over the four seasons, for the three sites (Table S2, Supplementary Material). In SR, the EPS fraction showed considerable seasonal variability, statistically relevant (Kruskall Wallis test, $p=0.044$ ), with very high accumulation values in autumn and summer and lower values in winter and spring. The RP and FR 
fractions showed rather homogeneous density values in all seasons, without statistically significant differences (Kruskall Wallis test, $p>0.05$ ). In MV, the EPS represented the most abundant category in all seasons, but it showed very high mean density values especially in autumn, with statistically significant differences (Kruskall Wallis test, $p=0.038$ ) compared to other seasons.

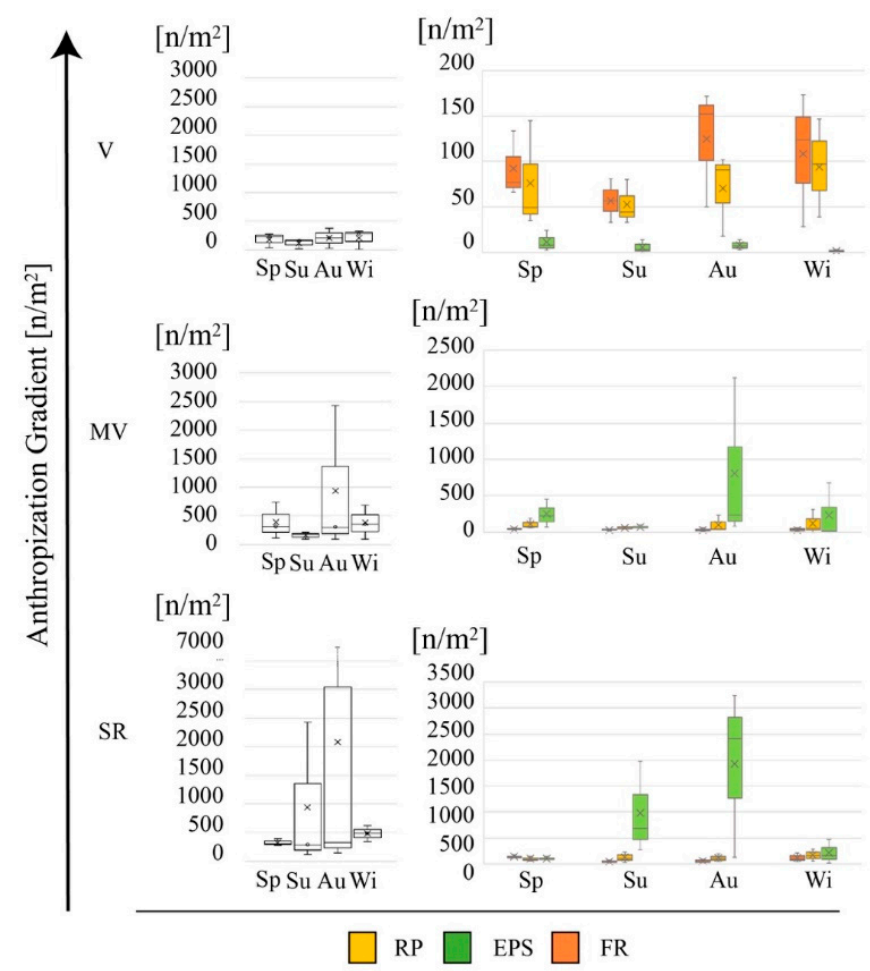

Figure 3. Distribution of MP density, expressed in number of items for square meter $\left(\mathrm{n} / \mathrm{m}^{2}\right)$ per site (SR, MV, V): considering the $3 \mathrm{MP}$ types together on the left, and separated on the right. (Sp = spring, $\mathrm{Su}=$ summer, $\mathrm{Au}=$ autumn, $\mathrm{Wi}=$ winter).

There were no significant differences in the density values of FR and RP among the four seasons considered (Kruskall Wallis test, $p>0.05$ ). In all seasons, however, the density values of the RP were higher than those of the FR. In V, we noted a different trend from the other two sites, as in all seasons, density values of the FR were higher than those of RP and EPS. In this site, no significant differences in the fraction of RP and EPS emerged (Kruskall Wallis test, $p>0.05$ ); only for FR did the Kruskall Wallis test yield a value slightly lower than the threshold $(p=0.049)$. In Table S2 (Supplementary Material) it is possible to see how the differences between the sites, for each one season, are statistically relevant for the EPS and FR types (Kruskall Wallis test always less than 0.05), while they are not for the RP.

Basically, of the three MP categories considered, only for the RP were there no statistically relevant differences in distribution, i.e., neither spatial (between site and site) nor temporal (for each site).

\subsection{Zonal Analysis}

Our sampling scheme allowed us to examine the distribution of MPs along the width of the three studied beaches, from shoreline to the upper parts, by selecting three zones within the beach: Dune (D), Intermediate (I) and Sea (Se) (with "Dune" we mean the area of beach just behind the dune, but not the area of the dune itself). The zonal analysis of MPs was carried out independently for the three types of MP sampled (Figure 4), since they had different hydrodynamic characteristics and dispersion modes. For all the three MP typologies, the trend was an accumulation on the upper parts (D), for all the beaches, except for EPS in V, which had the highest value in the I zone. 


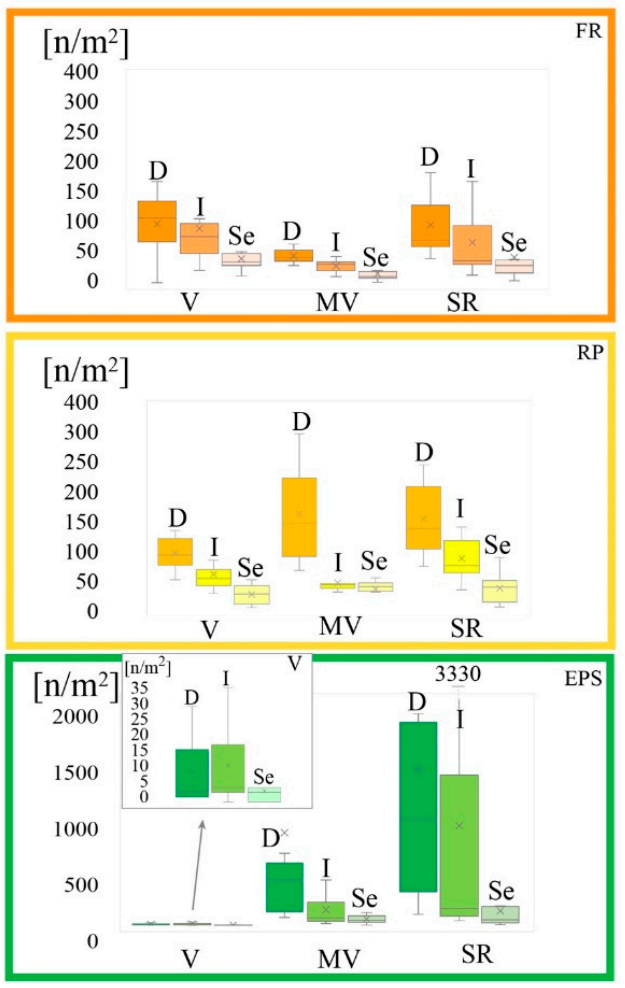

Figure 4. Distribution of FR (orange box on the top), RP (yellow box in the middle) and EPS densities (green box below), expressed in number of items for square meter $\left(\mathrm{n} / \mathrm{m}^{2}\right)$, per site $(\mathrm{SR}, \mathrm{MV}, \mathrm{V}$,) according to the beach zonal analysis (Dune: D, Intermediate: I, Sea: Se). The enlarged box shows in detail the situation of Viareggio for EPS fraction.

Table S3 (Supplementary Material) reports the obtained values and the results of the statistical analysis (Krushal-Wallis test). For FR and RP, significant differences were found in the distribution of MP density values in the three areas of the beach, for all three sites. For EPS, on the other hand, this applied to SR and MV sites, which also showed great variability (great dispersion of values and very high IQR difference), while it does not apply to $V$ site that was characterized by very low abundance of EPS particles and no significant distinctness in the distribution of EPS in the three different zones (Kruskall Wallis test, $p=0.188$ ). The statistical analysis also revealed significant differences between sites. For instance, comparing the density values of the sampled EPS in the D zone for the three sites (Kruskall Wallis test, $p=0.001$ ), as well as in the I zone (Kruskall Wallis test, $p=0.001$ ) and in the Se zone (Kruskall Wallis test, $p=0.005$ ). For FR, significant variances between the three sites existed only for the D zone, but not for the other two which were closer to the sea (Table S3, Supplementary Material). On the other hand, for the RP, there were no differences between the sites for any of the three areas.

Again, the RP were dissimilar from the other MP categories, showing more comparable behavior among sites than the other MP categories considered.

\subsection{Dimensional Analysis}

The fragmentation of the pieces of collected plastic, and therefore, the relative frequencies of the size classes, can be associated with the degree of degradation and the time spent on the beach. It is also related to the main fragmentation mechanisms acting in the environment, thus providing information for the implementation of better anti-pollution measures.

Two of the MP types present in our sample, FR and EPS, are subject to fragmentation starting from the macro-objects brought to the beach; therefore, we undertook dimensional characterization of them. As shown in Figure 5, the largest FR $(4-5 \mathrm{~mm})$ represents the most significant fraction for 
all seasons and in all considered sites, except for MV during winter. We found that, as the size class decreases, the abundance of the related fragments also decreases. For the EPS fraction, in contrast, no regular pattern in the abundance distribution of the sampled particles in relation to the four size classes is detectable (Figure 6); however, in general, the most abundant classes in all seasons are the intermediate ones.
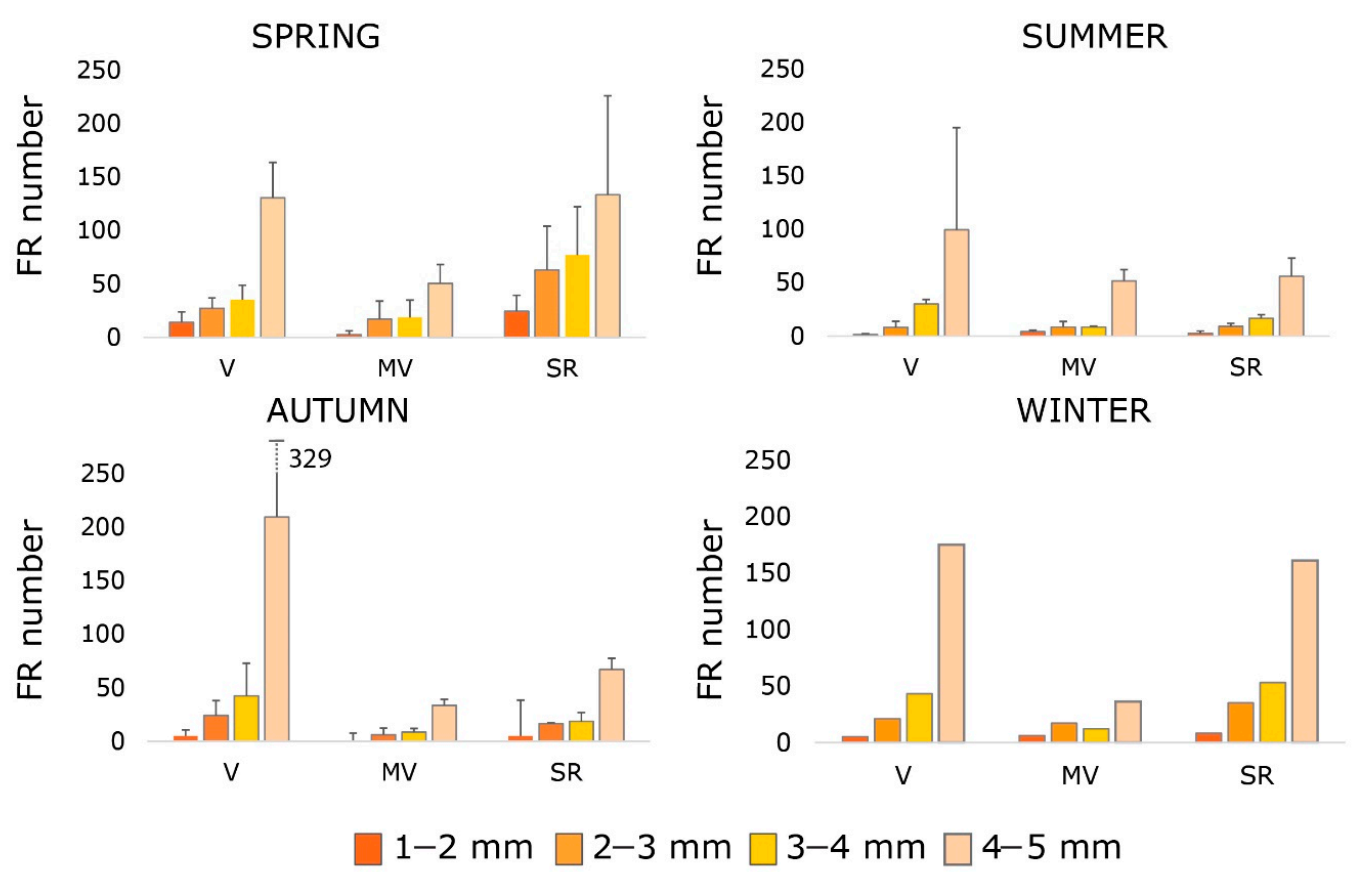

Figure 5. Seasonal analysis of the trend of the different size classes of fragments in the three sampled sites. In winter only one sampling was carried out, therefore there are no values for the standard deviation (data available in Table S4, Supplementary Material).

SPRING

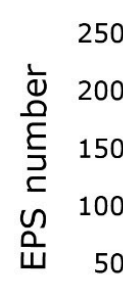

250

200

150

100

立 50

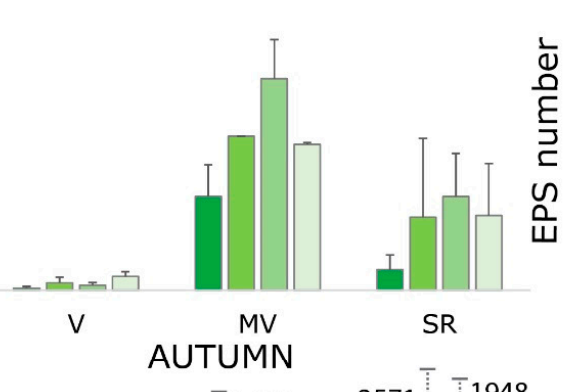

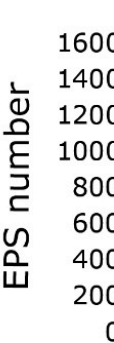

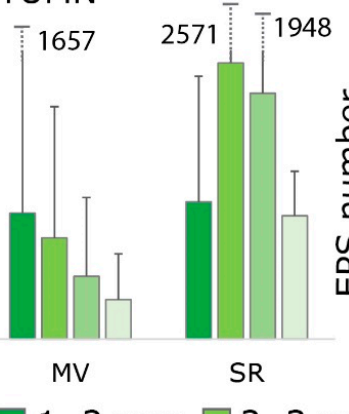

250
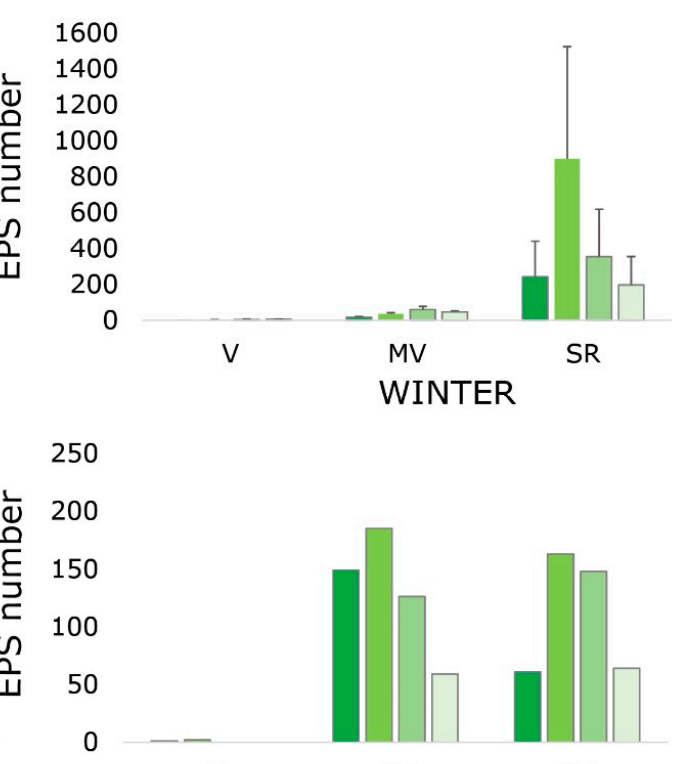

$\mathrm{V}$

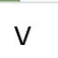

$\mathrm{SR}$

1-2 mm $\square$ 2-3 mm $\square$ 3-4 mm $\square$ 4-5 mm

Figure 6. Seasonal analysis of the trend of the different size classes of EPS in the three sampled sites. In winter only one sampling was carried out, therefore there are no values for the standard deviation (data available in Table S4, Supplementary Material). 


\subsection{Color Analysis}

The color classification of all items (excluding EPS) was done separately for FR and RP. RP, in fact, are marketed in two distinct types: precolored (additives) and "natural" (virgin polymer), typically glossy white and/or semitransparent. For the latter, the permanence in the environment, especially in highly oxidative one such as the sea, influences their degradation and leads to changes in aspect and color [102-106]. Accounting for color differences in the sampled RP can give information about the percentage between relatively new and aged RP. The latter, due to the supposedly longer stay at sea, may contain a considerable amount of Persistent Organic Pollutants (POPs) and absorbed pollutants, representing a danger for marine fauna [107-109]. RP were also classified according to their shape (89\% were round, $8 \%$ were cylindrical and 3\% disc-shaped) and for their appearance; some of them showed considerable weathering, being fractured, with porous surfaces which, in some cases, was so accentuated as to make the original appearance of the pellet unrecognizable (Figure S3, Supplementary Material). The vast majority (97.3\%) fell in the $2-4 \mathrm{~mm}$ size class, so no size classification was made for these MP categories. As for color classification, the RP results are shown in Figure 7.

Seasonal trends did not show appreciable changes for color distribution for any of the three sites, but a slight increase in the number of white resin pellets in winter for MV and, especially, for SR was observed. Combining the seasonal data in yearly values for each beach, we found that the relative frequency of pellets colors was consistent across the three sites: all of them were dominated by the "white" category (WH, 71\% in SR, 72\% in MV and 56\% in V), followed by "colored" (COL, $16 \%$ in SR, $18 \%$ in $\mathrm{MV}$ and $32 \%$ in $\mathrm{V}$ ), amber (AM, $7 \%$ in SR, $8 \%$ in MV and $7 \%$ in V) and "transparent-glossy" (TR-GL, $6 \%$ in SR, $2 \%$ in MV and $4 \%$ in V). The frequency values of the two predominant categories (WH and COL) were very similar for the two SR and MV sites, and the annual average values of the sampled RP were also very similar (Table S5, Supplementary Material). V site was slightly different both for number of sampled pellets and for relative proportion amongst the different color categories.

Regarding the color of plastic FRs, this parameter has been investigated in several studies as a possible factor related both to a greater or lesser tendency to fragmentation (correlated with additives and dyes in the polymer matrix of the objects [110], and to the possible selectivity for certain colors by marine species known to ingest plastic fragments [111]). In our chromatic analysis, for all sites, we noted the prevalence of white/glossy (WH-GL) FR, followed by blue (BL) and white old (WH-OD) and so by all the other colors, with GR as the most abundant (Figure 7). Combining seasonal data in yearly values, we determined that, in percentage, the most abundant color category (WH-GL) represented 31\% in SR, 36\% in MV and 36\% in V (Figure S4, Supplementary Material). It is interesting to note that BL and GR coloration are due to phthalocyanines, organic dyes that resist color loss very well, even in unfavorable environments such as at sea or on beaches under solar radiation (Figures S4, S7, S8, S11, S12, and S17 in Supplementary Material). Probably, due to the nature of other dyes used, the RE, YE, etc. pigments faded more than the BL and GR, and so they represented a lower percentage amongst the colored MPs. 

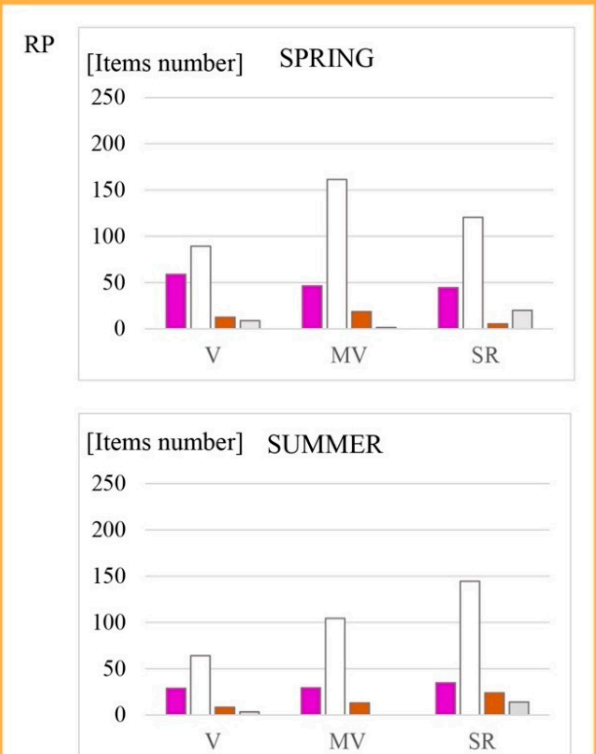

[Items number] AUTUMN

250

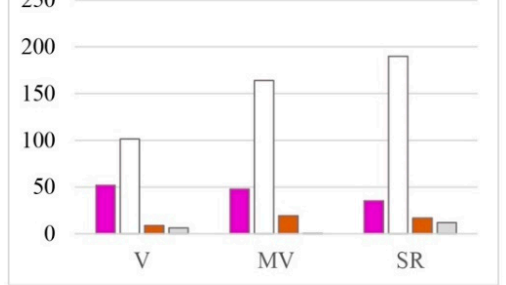

[Items number] WINTER

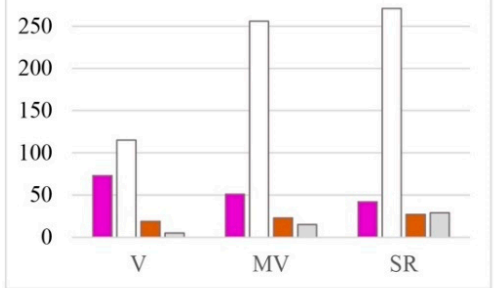

a $\mathrm{COL} \square \mathrm{WH} \square \mathrm{AM} \square \mathrm{TR}-\mathrm{GL}$

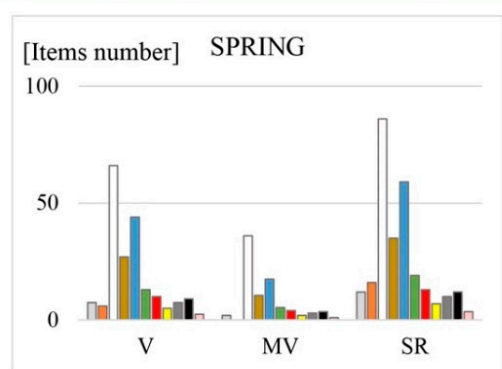

[Items number] SUMMER

100

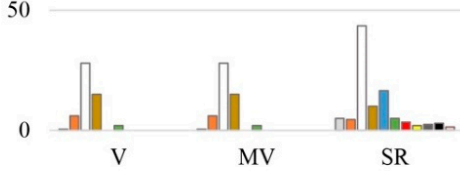

[Items number] AUTUMN

100

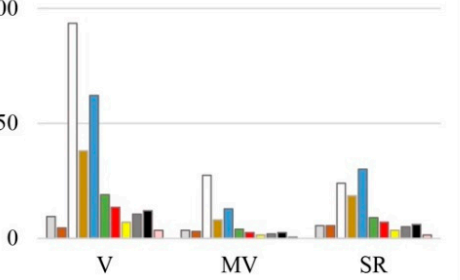

[Items number] WINTER

100

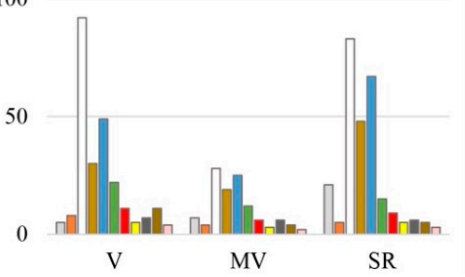

$\square$ TR-GL $\square \mathrm{AM} \quad \square$ WH-GL $=$ WH-OD

$=\mathrm{BL} \quad \square \mathrm{GR} \quad \mathrm{RE} \quad \square \mathrm{YE}$

$\because \mathrm{GY} \quad \square \mathrm{BK} \quad \square \mathrm{OT}$

Figure 7. Seasonal color distribution of RP and FR collected from each beach. Error bars have not been plotted in the graph for a better visualization of the data, but they are reported, with data, in Tables S5 and S6 in Supplementary Material.

\subsection{Polymeric Characterization}

Polymeric classification of the collected samples allowed us to ascertain which types of plastics were most frequently used and which were released into the environment. Since the analytical methodologies involve the use of advanced instrumentation and are typically very time-consuming, these measurements are generally carried out on a representative subset of the total samples. In our case, a representative subsample of the whole sample was analyzed by micro-Raman spectroscopy (for FR) and ATR (for RP) spectroscopy. To estimate the seasonality, samples belonging to one of the two spring sampling campaigns and to one of the two autumn sampling campaigns were chosen for the analysis. In this way, about one 
quarter of the total number of MP sampled in our study were considered for polymeric characterization, divided into FR (825 items), RP (1130 items) and EPS (6849 items (Table S7, Supplementary Material).

In Figure 8, we can see the polymeric percentages inside the beaches and in the two considered seasons. Apart from slight differences, the percentage of the different polymers were approximatively the same for both types of MPs (RP and FR) on all the beaches and for the two seasons.

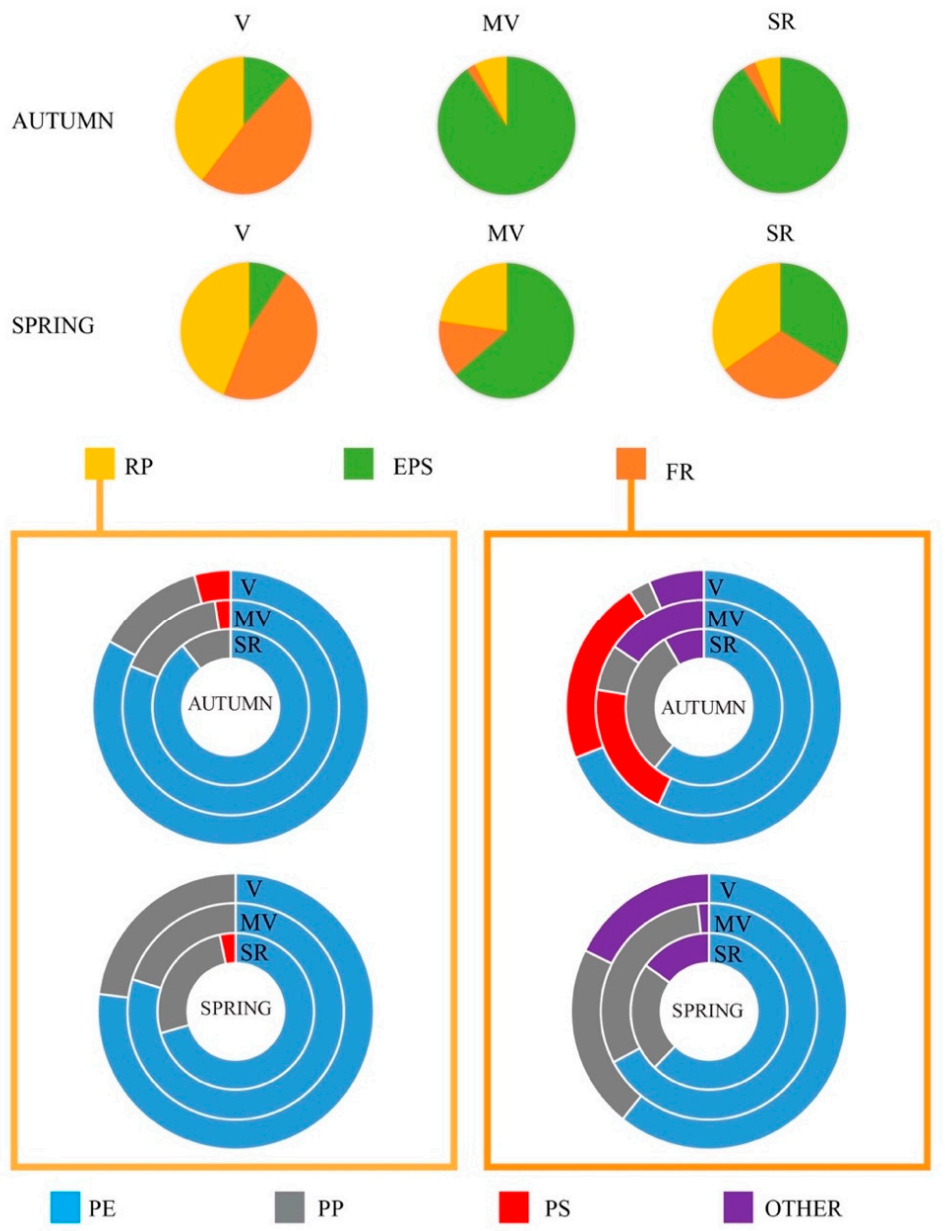

Figure 8. Pie charts of the main polymers of which the FR and RP are composed, divided by site (SR, MV, V) and season (spring and autumn). Data are available in Table S7 in Supplementary Material.

Polyethylene (PE) dominated all the samples, followed by Polypropylene (PP) and, particularly in the FR fraction, by Polystyrene (PS) and other polymers, such as Ethylene-vinyl acetate (EVA). By averaging the data of the two seasons, we found that EPS was the most abundant morphological and polymeric type (about $76 \%)$, followed by the fraction of RP (18\%, of which $78 \%$ in PE and $21 \%$ in PP, $1 \%$ other) and from the one of FR $(13 \%$, divided into the different polymeric categories according to the following proportions: $67 \% \mathrm{PE}, 25 \% \mathrm{PP}, 7 \%$ other). The most abundant polymer found was, therefore, PS in its expanded form (76\%), followed by PE (15\%), PP (5\%), and other polymers (including PS) in percentages of approximately $4 \%$. The ratio between PE and PP was 3:1.

A further analysis was made to investigate whether there was a correlation between the specific polymer and the size of the fragments, which could suggest a greater tendency to degrade or fracture of some types of polymers. In Figure 9 (bottom charts, on the right), we can see that, for PE, $40 \%$ of the samples (208 items) were between $4-5 \mathrm{~mm}, 33 \%$ (172 items) were between 3-4 mm, 28\% (143 items) between $2-3 \mathrm{~mm}$ and less than $1 \%$ were between 1-2 $\mathrm{mm}$ ( 3 items). For PP, in contrast, there was no evident differentiation according to dimension; the most abundant dimensional class was between $2-3 \mathrm{~mm}$. 


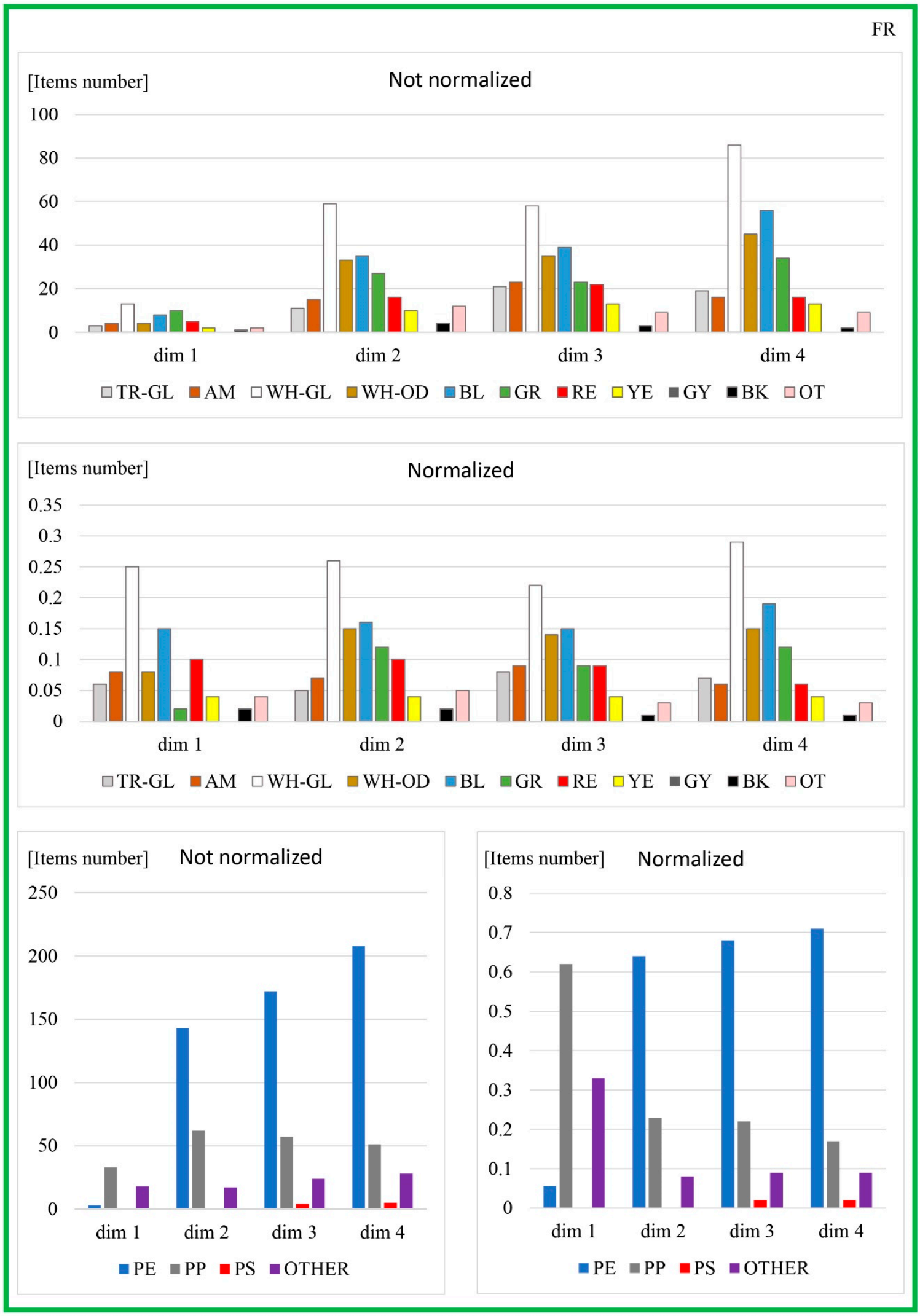

Figure 9. Distribution of polymeric types and color abundances in the different dimensional classes, for the sub-sample of which the polymeric characterization has been made. Two of the graphs reports values normalized to the total number of particles for each dimensional class: the very small differences, in percentage, amongst the color distribution of the four dimensional classes, clearly emerge. For polymeric type distribution, instead, larger differences are visible, specially between PP and PE. Data are available in Table S8 in Supplementary Material. 
From the same data, normalized to the total number of FRs for each dimensional class (bottom charts, on the left), consistent differences emerged amongst polymeric type distribution. Finally, a similar analysis was made to search for a possible correlation between the color of the fragment and its size, in order to understand if color parameters have any influence on the fragmentation of plastic objects (Figure 9, graphics on top); no correlation emerged between color distribution and dimensional class.

\section{Discussion}

One of the aims of this work was to overcome the lack of data concerning MPs on beaches in this part of the North-West Mediterranean Area, evaluating abundances, spatial and temporal distribution and characterization of LMPs sampled in three sites of North Tyrrhenian coast, located inside in the very sensitive area of the Pelagos Sanctuary. The beaches, similar in conformation, substrate type, dynamics of currents and wind and geographical location, were selected in order to represent different degrees of urbanization, to assess whether there were similarities and differences in MP abundance, and to identify the causes.

The analysis carried out showed that $\mathrm{SR}$, the natural $(\mathrm{Na})$ and protected beach with the lowest degree of urbanization, was the site with the highest MP density $\left(959 \pm 792\right.$ items $/ \mathrm{m}^{2}$;), followed by MV, the urbanized (Uz) site $\left(471 \pm 333\right.$ items $/ \mathrm{m}^{2}$ and V, the urban (U) beach $\left(175 \pm 42\right.$ items $\left./ \mathrm{m}^{2}\right)$, as visible in Figure 1. Due to the paucity of these kind or MP beach surveys in neighboring coasts, we can compare these values only with those found in a previous study on North Mediterranean beaches, in the Adriatic coast (mean density of $178.8 \mathrm{items} / \mathrm{m}^{2}$ for urban beaches in Slovenia, [60]).

The higher density of MPs found in the Na Site of SR, rather than in the Uz and U beaches of MV and $\mathrm{V}$, respectively, was probably related to the greater regularity of cleaning operations performed on the latter two beaches. Within the area of the SRPRK, in fact, the protection measures prevent the frequent removal of waste, which accumulates during the year, causing the paradoxical consequence of a higher average density of waste in protected beaches than in neighboring $U$ and $U z$ areas, as already reported in previous studies carried out in the same area on beached macro ML [68]. The subsequent fragmentation of unremoved waste probably contributes to the particularly high density of MPs in these areas [112]. This fact led us to consider the possibility that the MPAs could become a potential reservoir of MPs. Figure 1 shows a relationship between the gradient of "beach urbanization" and the calculated total mean density of MPs for each of the three sites of this work.

However, the three types of MPs considered in our classification had different physical characteristics and distinctive ways of being introduced and dispersed on the beach. The EPS, which arrives in the form of macro-objects, easily disintegrates into very small fragments which may be scattered by the wind and wave motion. Virgin plastic RP are primary MPs, have a higher density than EPS and their presence on beaches is linked to dispersion processes (at sea directly or carried by rivers) during storage or transport $[83,113,114]$. The FR are the result of the disintegration of plastic or multimaterial macroscopic objects, a process that, to a large extent, can occur directly in situ, due to either mechanical processes or photo-degradation [24,25]. In Figure 3, the obtained mean densities for each season and for each one of the three sites are plotted, together (graphs on the left) and individually (graphs on the right) for the three types of MPs. It is worth noting that from V to MV and then to SR, not only the total values of MP density (sum of the three categories) increased, for all seasons and as mean yearly value, but also the relative MP abundances changed: SR and MV were similar, with higher EPS values (especially in SR) characterized by a great dispersion. V showed, in contrast, the predominance of FR and very low number of EPS items, in all seasons. RP distribution was, instead, homogeneous for all sites. As in Figure 1, in Figure 3 there is also an "urbanization gradient"; the abundance and dispersion observed for the three types of MP seems to be associated with the three different types of beach ( $\mathrm{Na}, \mathrm{U}$ and $\mathrm{Uz}$ ).

A statistical analysis (Table S2, Supplementary Material) confirmed what emerged from Figure 3, i.e., that for RP, there are no statistically relevant differences in distribution, i.e., neither spatial (between 
site and site) nor temporal (for each site). This means that, during the year, the processes that leads to the accumulation of RP probably has similar modes at all sites, while this is not the case for the other two categories of MPs, whose accumulation must be affected by processes that act differently on the three beaches. The frequency and manner in which cleaning is carried out certainly has a significant influence, but the way in which waste arrives on the beach, e.g., coming from land (tourist attendance) or from the sea (proximity of rivers, ports, currents and winds), is also important. In this regard, Antunes et al. [114] identified correlations between these factors and the densities of different MP types on some beaches in Portuguese coast. FR seem to be related to tourism, which introduce macroplastics from the ground and, by trampling, can cause the fragmentation of coarse debris into smaller fragments, increasing their density in the surface layer. In our case, only V had the characteristics of a U beach. In $\mathrm{V}$, there was a greater abundance of FRs, which decreased, becoming comparable with RP, only during summer, probably due to the frequent cleaning activities that remove macroplastics; in the same site, the RP, connected to sea and river transport, did not show relevant seasonal variations (Table S2 in Supplementary Material). In MV and SR, in all seasons, the average density values of the RP were higher than those of the FRs, and neither category showed relevant differences among seasons (Table S2 in Supplementary Material). In these beaches (respectively $\mathrm{Uz}$ and $\mathrm{Na}$ ), tourism is less frequent, and the presence of two river mouths near these beaches (Arno and Serchio), both running through inland areas (Figure 1) characterized by the presence of companies producing plastic materials that make extensive use of virgin RP, is of great importance. These two beaches are also characterized by the large value of EPS, closely related to fishing activities; the fishing village of Marina di Pisa is at the Arno mouth, and in this area, the current is predominantly directed northward from the Tyrrhenian to the Ligurian Sea [115-117]. A higher density for EPS was found in autumn and winter, both in SR and MV (Figure 3), when abundant rainfall increases the flow of rivers, and as a consequence, the contribution of debris to the sea. The high frequency of storm surges can promote the beaching of debris dispersed at sea [112], and, at the same time, cleaning actions are not enforced. The large dispersion value of EPS, common to both sites, reflects the high dispersion capacity of this extremely light material, easily carried by the wind.

High densities values of EPS within MPs samples have also been found in Portuguese sites, similarly characterized by intense fishing activity [114]. In V, the low presence of EPS in all seasons derives from the removal of the coarsest fragments (typically EPS boxes or their macrofragments) during cleaning operations all year round. In addition, on this $U$ beach, natural obstacles, such as beached trunks, are quickly removed, and the wind can more easily move the EPS MPs from the beach. In beaches with less frequent cleaning, such as MV, or no cleaning, such as SR, the presence of beach trunks provides accumulation points for EPS macro-detritus that break down in situ. For this category of MP, the relevant differences between the three sites that emerge from the statistical analysis, for any season considered, were due to the differences in beach management. We found much higher values in SR than in MV for all seasons but, above all, during the summer, when cleaning takes place in MV but not in the Na site of SR.

The behavioral differences of FR, RP and EPS between the sites and seasons studied indicate that the processes that determine the accumulation of items can be independent from the site/season (for RP), or dependent on the site/season (for EPS and FR), in the latter case as influenced by contingent and local factors: supply of material from the ground due to the presence of tourists, fishing activities, fragmentation favored and accelerated by human trampling and mechanized cleaning operations.

Concerning "vertical" (or zonal) distribution inside the beach, the significant differences detected for the LMP accumulation in the three zones, and especially the highest density values detected in the $\mathrm{D}$ zone, agree with results of other studies dealing with the dynamics of the accumulation of ML on the beaches $[46,80]$. This is justified by the fact that the area closest to the shoreline is the most dynamic part of the beach, and is the most affected by the daily movement of the sea, while the intermediate area is affected by the medium intensity wave mode. The dune zone, on the other hand, is reached by the sea only during rather heavy sea storms which mostly occur in autumn. This area is also the place 
where, especially in $\mathrm{Na}$ or $\mathrm{Uz}$ beaches out of the holiday season, trunks and natural material act both as a trap for objects deposited by the waves [5]. In addition, the prevailing winds tend to carry some of the material to the inland area of the beach (EPS especially), finding an obstacle in the dunes and trunks [118]. In our study, all the three types of MPs considered show the same behavior with higher accumulation in the D zone. On the contrary, Karapanagioti et al. [104] found differences between RP and FR (they did not consider the EPS fraction) concerning the vertical distribution.

The analysis of the morphological properties of the sampled MP, in particular size and color, allows us to make several considerations. First of all, the dimensional analysis confirms that, depending on the nature of the initial macro-debris, the processes that act on them and produce MPs may be different and have different time scales. Figure 5 show that the predominant dimensional class, for FR, is the larger one, while for EPS (Figure 6) seems to be the intermediate/smaller one. Moreover, for FR the ratio among dimensional classes are the same for every season, while for EPS a seasonality emerges. In winter and autumn, the predominant classes are the smaller one (3-2,2-1), while during spring and summer the larger ones (3-4 and 2-3) prevail. This fact could be related to the strength of atmospheric agents, such as winds and storms (responsible for the fragmentation of macro-objects), during the bad seasons. The crumbling of EPS is in fact a process that has a very rapid time scale, and different weather conditions have visible effects on a short period, while this does not apply to fragmentation process of macroplastic. Confirming this in MV we found, during summer, a very low quantity of EPS (Figure 6) due, as already said, to the cleaning actions that typically remove large EPS objects from this $\mathrm{Uz}$ beach. As these operations start in late spring, the rapid (few months) decline of EPS fragments on the beach is possible only if the fragmentation process is a fast process.

In previous works dealing with MPs, color is mentioned, in some case, as incidental data only; in other ones, on the contrary, it is stressed the role it can have regarding a possible preferential selection mechanism for ingestion by marine biota [111,119]. Moreover, some authors speculated that an emerging correlation between color and fragment dimension could be a sign that the presence of particular dyes in the polymeric matrix affects the degradation and fragmentation process [110]. For FR, we found a good agreement with the color percentages reported in a study that devoted a lot of attention on color classification [100]. In particular, by combining our distinct classes of "White" colors in a unique one (WH), as they do, we find that the color class sequence from the most abundant to the lesser one is in good agreement with their, even if the percentages are different (our WH correspond to $50.5 \%$, their WH the $71.8 \%$; our BL is $20 \%$ vs. $8.5 \%$ of their value; our GR is $7.0 \%$ vs. $7.5 \%$; our RE is $4.3 \%$ vs. $2.6 \%$; our YE $2.2 \%$ vs. $1.2 \%$ ). Another difference concerns the black colored plastic pieces: we find few of them while, on the contrary, Young and Eliott [100] found that they represented 7.3\% of their samples. Moreover, besides distinguishing different types of White (WH-GL for the "new" white fragments, and WH-OD for the "older" ones), in our sample we also distinguished the Amber fragments. This color is the one that plastic originally Transparent and Glossy assumes due to ageing, presumably after a long stay in an oxidizing environment. It is the same color that we find also in some aged resin pellets [81,102-106]. The other colors, that we put together in a unique category (OT) where $4.2 \%$ of the total, while Young and Eliott [100] further classified them in orange, purple and brown, for a total of $1.1 \%$. Interesting is the agreements amongst the most populated "colored" class: both in our and in Young \& Eliott [100] classification, BL and GR fragments are the most frequent pigmented MP found. This is probably due to the capacity of Phthalocyanines dyes to better withstand the effect of both marine environment and solar radiation. In any case, the different percentages of the various color classes coming from different studies are, in our opinion, difficult to compare. It is hard to think of a color classification that is objectively unique and that can serve as a standard. In addition, the fact that there are many possible shades for the same color can lead, during classification process, to some subjective factor in placing objects in one color class rather than another.

As concern RP, a particular coloration can be indicative of origin, degree of degradation and/or contact with pollutants; the "amber color" degree (often called "yellowing") has been used as parameter for determining the time a plastic pellet has remained in the environment, leading some authors 
to propose pellets as "environmental tracers" for hydrophobic compounds pollution [102-104,106]. Some of them proposed a subdivision into classes of "yellowing" based on the different gradations of the "amber color" reached by pellets due to aging, in order to correlate them with the amount of POPs absorbed during their stay in the marine environment. In fact, the increased presence of toxic compounds in dark colored RP particles is of concern, as many organisms are exposed to these materials through accidental ingestion or trophic transfer $[119,120]$. Since our aim was not such kind of investigation, we limited ourselves to a less detailed colorimetric classification (see Material and Methods). The results show that in our samples we have an abundance of White RP. These pellets are relatively new, since the original color (TR-GL) become Amber only after about 6 months [105]. We have not found large seasonal variations to this trend and this confirms the general picture already described, i.e., that the pellets, being brought from the sea and coming mainly from the rivers, are subject to fewer variations both spatial (site to site) and seasonal, not affected by local dynamics that occur on the beaches, such as fragmentation, cleaning activities, etc. Probably, the slight increase detected in the number of white RP found in MV during winter is due to the higher contribution of this material in that season by the Arno River, along which many small and medium industries producing plastic material are located.

Regarding polymeric type, there are a wide range of polymers annually produced. Some of them float on seawater (PE, PP and, mostly, EPS, PS in a lesser extent), and consequently are able to travel long distances being found far away from their sources [6]. PVC, PA, PET or PVA may sink, due to their intrinsic high density, potentially accumulating in benthic sediments. On the beach is very common to find RP of PE and PP, with a ratio of about 3:1. Very few RP of PS can be found and practically none of other materials. The finds of this study confirm the ratio between PE and PP (Figure 8 and Table S7 in Supplementary Material). As regard FR, as they can be produced by fragmentation of material directly on the beach, we expect to find also other polymers than PE, PP and PS. However, PE and PP are the most widely used polymers in plastic products (particularly used in the packaging industry, such as bottles, packaging, etc.), as confirmed by studies on MP characterization in beaches and in the sea. These studies agree on the prevalence of PE MPs, followed by PP and other categories, with a 3:1 ratio between the first two in the Mediterranean area [56,61]. Recent works by Young and Elliott [100] in the Hawaii islands, or Karthik et al. [121] in the coasts of India, found a ratio between one-ninth and a one-third between PE and PP in the beach FR. Our finds agree with the Mediterranean results. Moreover, we do not find a distinctly prevailing polymeric differentiation between beaches, neither in general nor within the two seasons of the subsample considered in performing the polymeric analysis (Figure 8).

Finally, looking at Figure 9, we note that, for the subsample of chemically characterized FR (This subsample presents a color distribution very similar to the one of global sample (Figure S4 in Supplementary Material). This supports our assumption that the results we found for the subsample of which we also know the polymeric types can be considered valid also for the whole FR sample.), there is about the same number of items for every dimensional class of PP, while for PE the larger FR class contains a larger number of items. Differences amongst dimensional classes for the polymeric distribution emerges also looking the normalized graph in Figure 9. PE items could so have fracturing mechanisms different from PP objects. For the same sample of FR, the color distribution does not seem to present different trend for the different dimensional classes; especially, from the normalized graph (Figure 9) very small percentage differences emerges. The frequencies of FR colors seem to be consistent across all four size classes (Figure 9 and Figure S4, Supplementary Material), confirming the results of Young and Elliot [100].

\section{Conclusions}

In this study, we have shown the results of one year of LMP sampling in an area of particular environmental interest, included in the Pelagos Sanctuary, a highly protected Marine Park which is particularly sensitive to MP pollution, due to the high number of marine mammalians it hosts. 
Although several previous works have carried out off-shore MP monitoring in the waters of this area, data on the presence, type and distribution of MP in the coastal area were not available, and the present work hopes to help fill this gap.

Our data evidenced an anticorrelation between degree of urbanization of the sampled site and the estimated density of LMP in it. These results confirm what has already been found regarding macrodetritus by Giovacchini et al. [68] in the same area of Tyrrhenian coast, and are probably due to the different management strategies for each site.

However, the scenario that emerges from our study is more complex, as in order to understand which factors influence the spatial and temporal distributions of LMPs on beaches, it is necessary to consider not only the total density, but also the composition of the sampled particles. A statistical analysis highlighted, in fact, that the seasonality and the degree of urbanization of the beaches affect FR, EPS and RP differently, and, moreover, the proximity of rivers and fishing activities also need to be considered $[58,66]$. This fact was further confirmed by a dimensional analysis performed on EPS and FR, highlighting how the fragmentation of macrodetritus, and the consequent dispersion and accumulation of second-generation MP, follow different processes depending on the source material.

An important outcome of our study is that RP represent a large percentage amongst LMPs sampled in beaches, in all seasons. They are mainly discharged into the sea through river inputs, and, being first generation MPs, their dispersion could be reduced through the adoption of stricter rules and controls on their transport and stocking.

Contrary to the hypothesis of some previous authors, our data did not show any correlation between the color of the MP and their size, while there seems to be a relationship between this and polymeric type. So, while color does not seem a good parameter to indicate a lower or higher propensity to fracture in plastic objects, it may be fundamental, in further investigation, to take into account more deeply the processes of degradation of different polymers in the marine environment, in order to better understand, and also predict, which objects are more susceptible to fragmenting and on what time scale. In this sense, polymeric analyses of MPs are important, and it is important to be able to perform them on a large number of samples, and quickly. This is why in our study, the feasibility of a mobile Raman system was tested on the FR samples. This approach proved to be reliable, reveling several advantages: it can be used directly, without sample pretreatment, does not require the absence of ambient light (as is necessary for the standard laboratory Raman instrument); and it allows easy recognition of polymers, together with the possible presence of inorganic substances. These results suggest the value of using a portable instrument during the sampling for prescreening procedures and to optimize the collection itself. The role of technology (including the Raman spectroscope) for analyses, which, today offers the possibility of performing remote sensing analyses and in-the-field analysis in several scientific fields [122,123], should certainly be increased. All these improvements could speed up the identification of specific types of waste, helping in the identification of such materials that have the potential to cause major environmental problems.

Marine pollution is everybody's problem, and as such, there is a strong need to find different solutions that must involve all actors (civil society, academia, industry, etc.). As researchers, we can make our contribution by increasing awareness of the problem and disseminating the results as widely as possible [124]. These results should then be the starting point for different stakeholders to implement the social policies and community actions which are necessary to reduce the negative impacts of plastic use in modern society as much as possible.

Supplementary Materials: The following are available online at http://www.mdpi.com/2073-4441/12/12/3389/s1. Table S1. Total microplastics analysis $(n=21)$. Table S2. Analysis by type of plastic $(n=21)$. Table S3. Zonal Analysis $(n=21)$. Table S4. Abundance of FR and EPS belonging to the different size classes in the four seasons. Table S5. Seasonal and yearly abundance of resin (RP) divided into different colorimetric classes, for each beach. Table S6. a. Seasonal abundance of fragments (FR) divided into different colorimetric classes, for each beach. Table S6. b. Percentage abundance of fragments (FR) divided into different colorimetric classes, for each beach, Table S7. Main polymers detected in fragments (FR) and resin pellets (RP) for the items analyzed by infrared spectroscopy (sub-sample). Table S8_a. Number of fragments (FR) of different polymeric type for each dimensional category (as absolut value and as value normalized within dimensional category). Table S8. b. Number of fragments (FR) of 
different color classes for each dimensional category (as absolut value and as value normalized within dimensional category). Table S9. The table shows, for Polyethylene, the molecular vibrations. Table S10. The table shows, for Polypropylene, the molecular vibrations. Table S11. The table shows, for Polystyrene, the molecular vibrations. Table S12. The table shows, for Ethylene, the molecular vibrations. Table S13. The table shows, for Ethylene Vinyl Acetate (EVA), the molecular vibrations. The Spectra is reported in Figure S15. Table S14. The table shows, for Epoxy Resin, the molecular vibrations, The Spectra is reported in Figure S16. Figure S1. The sampling design is multifactorial, where the site factor is crossed (orthogonal) with the seasonality, and the Zone factor is hierarchical. Figure S2. Beaches images. SR is San Rossore beach. Figure S3. A few other examples of the RP type of the sampled MP, with the different colour shades due to ageing, from Transparent-Glossy (TR-GL), to White (WH), and then Amber (AM). Figure S4. Frequencies of color classes for the three sites. Figure S5. Raman spectrum from a fragment of polyethylene. Figure S6. Raman spectrum of a fragment of Polyethylene with the characteristic peak of Titanium Oxide (TiO2) at $143 \mathrm{~cm}^{-1}$. Figure S7. Spectrum of a fragment of Polyethylene with green pigment. Figure S8. Spectrum Raman of a fragment of Polypropylene with blue phthalocyanine $\mathrm{Cu}(\mathrm{C} 32 \mathrm{H} 16 \mathrm{~N} 8)$. Figure S9. Raman spectrum of a fragment of Polypropylene. Figure S10. Spectrum Raman of a fragment of Polypropylene with Titanium Oxide (TiO2), peaks at $143 \mathrm{~cm}^{-1}$ and $639 \mathrm{~cm}^{-1}$. Figure S11. Raman spectrum of a fragment of Polypropylene with green phthalocyanine $\mathrm{Cu}(\mathrm{C} 32 \mathrm{H} 16 \mathrm{~N} 8)$. Figure S12. Spectrum Raman of a fragment of Polypropylene with blue phthalocyanine $\mathrm{Cu}(\mathrm{C} 32 \mathrm{H} 16 \mathrm{~N} 8)$. Figure S13. Raman Spectrum of a fragment of Polystyrene. Figure S14. Ethylene Raman Spectrum. Figure S15. Raman spectrum of a fragment of ethylene vinyl acetate. Figure S16. Raman spectrum of an epoxy resin fragment. Figure S17. Example of a fragment classified as a pigment.

Author Contributions: Conceptualization, S.M. and M.A.; methodology, M.A., S.M., S.L. and V.P.; software, M.L., G.B. and C.C.; validation, M.L., S.M., S.L. and V.P.; formal analysis, M.L., S.M., S.L. and V.P.; investigation, S.M., M.A., M.L., G.B., C.C., S.L. and V.P.; resources, M.A., S.M., S.L. and V.P.; data curation, M.A., S.L., V.P. and M.L.; writing-original draft preparation, S.M., M.L. and M.A.; writing-review and editing, S.M., M.L., M.A., S.L. and V.P.; supervision, S.M., M.A., S.L. and V.P.; project administration, S.M. All authors have read and agreed to the published version of the manuscript.

Funding: The activities carried out during this research are part of those carried out within the SeaCleaner project (https://sites.google.com/view/seacleaner/home-page), partly funded by the DLTM Pole, CNR-ISMAR and the European Commission's Framework Programme for Research and Innovation H2020 (2014-2020)-Marie Skłodowska-Curie Actions, Directorate-General for Education and Training, and Culture, under Grant Agreement No 633306.

Acknowledgments: We want to thank in particular the Park of Migliarino, Massacciuccoli and San Rossore (SRPRK) for giving us the opportunity to perform our monitoring in areas of high protection and forbidden to the public. The authors state that the data supporting the results of this study are included in the Supplementary Material (also avalilable in the master thesis "Caratterizzazione e analisi dell'abbondanza e della distribuzione di microplastiche in tre spiagge dell'alto Tirreno con diverso grado di urbanizzazione", Carlotta Como, Università degli studi di Torino, Dipartimento di Scienze della Vita e Biologia dei Sistemi, tutors Francesca Bona and Marinella Abbate, and in the master thesis "Approccio sperimentale per la classificazione e monitoraggio di detriti plastici nell'ambiente marino e costiero. Caso studio: Parco di Migliarino, San Rossore, Massaciuccoli e zone limitrofe", Gabriele Bernardi, Università di Pisa, Corso di Laurea in Scienze Ambientali, tutors Alessio Cerrarini and Stefano Legnaioli,) and that the original dataset, before statistical processing, is available on request.

Conflicts of Interest: The authors declare no conflict of interest. The funders had no role in the design of the study; in the collection, analyses, or interpretation of data; in the writing of the manuscript, or in the decision to publish the results.

\section{References}

1. Galgani, F.; Hanke, G.; Maes, T. Global Distribution, Composition and Abundance of Marine Litter. In Marine Anthropogenic Litter; Bergmann, M., Gutow, L., Klages, M., Eds.; Springer: Cham, Switzerland, 2015. [CrossRef]

2. Bracha, L.; Deixonneb, P.; Bernardb, M.-F.; Durandc, E.; Desjeand, M.-C.; Pereza, E.; van Sebillee, E.; ter Hallea, A. Anticyclonic eddies increase accumulation of microplastic in the North Atlantic subtropical gyre. Mar. Pollut. Bull. 2018, 126, 191-196. [CrossRef]

3. Van Sebille, E.; England, M.H.; Froyland, G. Origin and evolution of the ocean garbage patches derived from surface drifter data. Environ. Res. Lett. 2012, 7, 044040. [CrossRef]

4. Cozar, A.; Echevarria, F.; Gonzalez-Gordillo, J.I.; Irigoien, X.; Ubeda, B.; Hernandez-Leon, S.; Palma, Á.T.; Navarro, S.; García-de-Lomas, J.; Ruiz, A.; et al. Plastic debris in the open ocean. Proc. Natl. Acad. Sci. USA 2014, 111, 10239-10244. [CrossRef]

5. Poeta, G.; Battisti, C.; Acosta, A.T.R. Marine litter in Mediterranean sandy littorals: Spatial distribution patterns along central Italy coastal dunes. Mar. Pollut. Bull. 2014, 89, 168-173. [CrossRef] 
6. Zhang, W.; Zhang, S.; Wang, J.; Wang, Y.; Mu, J.; Wang, P.; Lin, X.; Ma, D. Microplastic pollution in the surface waters of the Bohai Sea, China. Environ. Pollut. 2017, 231, 1541-1548. [CrossRef] [PubMed]

7. Van Cauwenberghe, L.; Vanreusel, A.; Mees, J.; Janssen, C.R. Microplastic pollution in deep-sea sediments. Environ. Pollut. 2013, 182, 495-499. [CrossRef]

8. Galgani, F.; Leaute, J.; Moguedet, P.; Souplet, A.; Verin, Y.; Carpentier, A.; Goraguer, H.; Latrouite, D.; Andral, B.; Cadiou, Y.; et al. Litter on the Sea Floor Along European Coasts. Mar. Pollut. Bull. 2000, 40, 516-527. [CrossRef]

9. Mifsud, R.; Dimech, M.; Schembri, P.J. Marine litter from circalittoral and deeper bottoms off the Maltese islands (Central Mediterranean). Mediterr. Mar. Sci. 2013, 14, 298-308. [CrossRef]

10. Obbard, R.W.; Sadri, S.; Wong, Y.Q.; Khitun, A.A.; Baker, I.; Thompson, R.C. Global warming releases microplastic legacy frozen in Arctic Sea ice. Earth's Future 2014, 2, 315-320. [CrossRef]

11. Lusher, A.L.; Tirelli, V.; O'Connor, I.; Officer, R. Microplastics in Arctic polar waters: The first reported values of particles in surface and sub-surface samples. Scientific Reports. Sci. Rep. 2015. [CrossRef]

12. Li, J.; Liu, H.J.; Chen, P. Microplastics in freshwater systems: A review on occurrence, environmental effects, and methods for microplastics detection. Water Res. 2018, 137, 362-374. [CrossRef]

13. Wagner, M.; Lambert, S. Freshwater Microplastics. Emerging Environmental Contaminants? In The Handbook of Environmental Chemistry Book Series 2018 (HEC, Volume 58); Springer: Berlin/Heidelberg, Germany, 2018; ISBN 978-3-319-61615-5.

14. Sighicelli, M.; Pietrelli, L.; Lecce, F.; Iannilli, V.; Falconieri, M.; Coscia, L.; Di Vito, S.; Nuglio, S.; Zampetti, G. Microplastic pollution in the surface waters of Italian Subalpine Lakes. Environ. Pollut. 2018, 236, 645-651. [CrossRef]

15. Bellasi, A.; Bindi, G.; Poza, A.; Galafassi, S.; Voltaand, P.; Bettinetti, R. Microplastic Contamination in Freshwater Environments: A Review, Focusing on Interactions with Sediments and Benthic Organisms. Environments 2020, 7, 30. [CrossRef]

16. Barboza, L.G.A.; Cózar, A.; Gimenez, B.C.G.; Barros, T.L.; Kershaw, P.J.; Guilhermino, L. Macroplastics pollution in the marine environment. In World Seas: An Environmental Evaluation, 2nd ed.; Sheppard, C., Ed.; Academic Press: Cambridge, MA, USA, 2019; Chapter 7; pp. 305-328.

17. Tekman, M.B.; Gutow, L.; Macario, A.; Haas, A.; Walter, A.; Bergmann, M. LITTER BASE/AW Database; Alfred-Wegener-Institut Helmholtz-Zentrum für Polar- und Meeresforschung: Bremerhaven, Germany, 2019; Available online: https://litterbase.awi.de/litter_detail (accessed on 29 November 2020).

18. Cole, M.; Lindeque, P.; Halsband, C.; Galloway, T.S. Microplastics as contaminants in the marine environment: A review. Mar. Pollut. Bull. 2011, 62, 2588-2597. [CrossRef]

19. Hidalgo-Ruz, V.; Gutow, L.; Thompson, R.C.; Thiel, M. Microplastics in the marine environment: A review of the methods used for identification and quantification. Environ. Sci. Technol. 2012, 46, 3060-3075. [CrossRef]

20. GESAMP. Sources, Fate and Effects of Microplastics in the Marineenvironment: A Global Assessment; Kershaw, P.J., Ed.; (IMO/FAO/UNESCO-IOC/UNIDO/WMO/IAEA/UN/UNEP/UNDP Joint Group of Experts on the Scientific Aspects of Marine Environmental Protection); International Maritime Organization: London, UK, 2015; Available online: http://ec.europa.eu/environment/marine/good-environmental-status/descriptor-10/ pdf/GESAMP_microplastics\%20full\%20study.pdf (accessed on 29 November 2020).

21. Hartmann, N.B.; Hüffer, T.; Thompson, R.C.; Hassellöv, M.; Verschoor, A.; Daugaard, A.E.; Rist, S.; Karlsson, T.; Brennholt, N.; Cole, M.; et al. Are wespeaking the same language? Recommendations for a defi-nition and categorization framework for plastic debris. Environ. Sci. Technol. 2019, 53, 1039-1047. [CrossRef]

22. Nel, H.A.; Froneman, P.W. A quantitative analysis of microplastic pollution along the South-Eastern coastline of South Africa. Mar. Pollut. Bull. 2015. 101, 274-275.

23. NOAA. Available online: http://wwwmarinedebris.noaa.gov (accessed on 29 November 2020).

24. Andrady, A.L. Microplastics in the marine environment. Mar. Pollut. Bull. 2011, 62, 1596-1605. [CrossRef]

25. Andrady, A.L. The plastic in microplastics: A review. Mar. Pollut. Bull. 2017, 119, 12-22. [CrossRef]

26. Ryan, P.G. A Brief History of Marine Litter Research. In Marine Anthropogenic Litter; Bergmann, M., Gutow, L., Klages, M., Eds.; Springer: Cham, Switzerland, 2015; ISBN 978-3-319-16510-3. [CrossRef]

27. Fendall, L.S.; Sewell, M.A. Contributing to marine pollution by washing your face: Microplastics in facial cleansers. Mar. Pollut. Bull. 2009, 58, 1225-1228. [CrossRef]

28. Moore, C.J. Synthetic polymers in the marine environment: A rapidly increasing, long-term threat. Environ. Res. 2008, 108, 131-139. [CrossRef] 
29. Shiber, J.G. Plastic pellets on the coast of Lebanon. Mar. Pollut. Bull. 1979, 10, 28-30. [CrossRef]

30. Lebreton, L.C.M.; van der Zwet, J.; Damsteeg, J.-W.; Slat, B.; Andrady, A.; Reisser, J. River plastic emissions to the world's oceans. Nat. Commun. 2017, 8, 15611. [CrossRef]

31. Pierdomenico, M.; Casalbore, D.; Chiocci, F.L. Massive benthic litter funnelled to deep sea by flash-flood generated hyperpycnal flows. Sci. Rep. 2019, 9, 5330. [CrossRef]

32. OSPAR. Guideline for Monitoring Marine Litter on the Beaches in the OSPAR Maritime Area; OSPAR Commission: London, UK, 2010.

33. Galgani, F.; Hanke, G.; Werner, S.; Oosterbaan, L.; Nilsson, P.; Fleet, D.; Kinsey, S.; Thompson, R.C.; van Franeker, J.; Vlachogianni, T.; et al. Guidance on Monitoring of Marine Litter in European Seas; Joint Research Centre IES Scientific and Policy Reports, Via Enrico Fermi 2749, I-21027 Ispra (VA), Italy; European Commission: Brussels, Belgium, 2013.

34. GESAMP. Guidelines for the Monitoring and Assessment of Plastic Litter in the Ocean. J. Ser. GESAMP Rep. Stud. 2019. Available online: http://www.gesamp.org/publications/guidelines-for-the-monitoring-andassessment-of-plastic-litter-in-the-ocean (accessed on 29 November 2020).

35. Lebreton, L.C.M.; Greer, S.D.; Borrero, J.C. Numerical modelling of floating debris in the world's oceans. Mar. Pollut. Bull. 2012, 64, 653-661. [CrossRef]

36. Cannizarro, L.; Garofalo, G.; Giusto, G.; Rizzo, P.; Levi, D. Qualitative and quantitative estimate of solid waste in the channel of Sicily. In Proceedings of the Second International Conference on the Mediterranean Coastal Environment, MED-COAST 95, Tarragona, Spain, 24-27 October 1995.

37. Galgani, F.; Jaunet, S.; Campillo, A.; Guenegan, X.; His, E. Distribution and abundance of debris on the continental shelf of the North-western Mediterranean Sea. Mar. Pollut. Bull. 1995, 30, 713-717. [CrossRef]

38. Galgani, F.; Souplet, A.; Cadiou, Y. Accumulation of debris on the deep sea floor of the French Mediterranean coast. Mar. Ecol. Prog. Ser. 1996, 142, 225-234. [CrossRef]

39. Gardiner, V. La pollution de plages a Malte. Mediterranée. Tour. Loisirs 1996, 84, 353-356.

40. Tudor, D.T.; Williams, A.T.; Randerson, P.; Ergin, A.; Earll, R.E. The use of multivariate statistical techniques to establish beach debris pollution sources. J. Coast. Res. 2002, 725, 716-725. [CrossRef]

41. Aliani, S.; Molcard, A. Floating debris marine debris: Microbenthic species in the Western Mediterranean Sea. Hydrobiologia 2003, 503, 59-67. [CrossRef]

42. Barnes, D.K.A. Remote Islands Reveal Rapid Rise of Southern Hemisphere Sea Debris. Sci. World J. 2005, 5, 135820. [CrossRef] [PubMed]

43. Martinez-Ribes, L.; Basterretxea, G.; Palmer, M.; Tintoré, J. Origin and abundance of beach debris in the Balearic Islands. Sci. Mar. 2007, 71, 305-314. [CrossRef]

44. Ariza, E.; Jiménez, J.A.; Sardà, R. Temporal evolution of beach waste and litter during bathing season on the Catalan coast. Waste Manag. 2008, 28, 2604-2613. [CrossRef] [PubMed]

45. Koutsodendris, A.; Papatheodorou, A.; Kougiourouki, O.; Georgiadis, M. Benthic marine litter in four Gulfs in Greece, Eastern Mediterranean; abundance, composition and source identification. Estuar. Coast. Shelf Sci. 2008, 77, 501-512. [CrossRef]

46. Turner, A.; Holmes, L. Occurrence, distribution and characteristics of beached plastic production pellets on the island of Malta (central mediterranean). Mar. Pollut. Bull. 2011, 62, 377-381. [CrossRef]

47. Collignon, A.; Hecq, J.-H.; Galgani, F.; Voisin, P.; Collard, F.; Goffart, A. Neustonic microplastic and zooplankton in the North Western Mediterranean Sea. Mar. Pollut. Bull. 2012, 64, 861-864. [CrossRef]

48. Faure, F.; Corbaz, M.; Baecher, H.; de Alencastro, L.F. Pollution due to plastics and microplastics in Lake Geneva and in the Mediterranean Sea. Arch. Dis. Sci. 2012, 65, 157-164.

49. Guvem, O.; Gulyavuz, H.; Deval, M.C. Benthic Debris Accumulation in Bathyal Grounds in the Antalya Bay, Eastern Mediterranean. Turk. J. Fish. Aquat. Sci. 2013, 13, 43-49.

50. Kordella, S.; Geraga, M.; Papatheodorou, G.; Fakiris, E. Litter composition and source contribution for 80 beaches in Greece, Eastern Mediterranean: A nationwide voluntary clean-up campaign. Aquat. Ecosyst. Health Manag. 2013, 16, 111-118. [CrossRef]

51. Vianello, A.; Boldrin, A.; Guerriero, P.; Moschino, V.; Rella, R.; Sturaro, A.; Da Ros, L. Microplastic particles in sediments of Lagoon of Venice, Italy: First observations on occurrence, spatial patterns and identification. Estuar. Coast. Shelf Sci. 2013, 130, 54-61. [CrossRef] 
52. Collignon, A.; Hecq, J.-H.; Galgani, F.; Collard, F.; Goffart, A. Annual variation in neustonic micro and meso particles and zooplankton in the Bay of Calvi (mediterraneum-Corsica). Mar. Pollut. Bull. 2014, 79, $293-298$. [CrossRef] [PubMed]

53. Poeta, G.; Battisti, C.; Bazzichetto, M.; Acosta, A.T.R. The cotton buds beach: Marine Litter assessment along the Tyrrhenian coast of central Italy following the marine strategy framework directive criteria. Mar. Pollut. Bull. 2016, 113, 266-270. [CrossRef]

54. Suaria, G.; Aliani, S. Floating debris in the Mediterranean Sea. Mar. Pollut. Bull. 2014, 86, 494-504. [CrossRef]

55. Laglabauer, B.J.L.; Franco-santos, R.M.; Andreu-cazenave, M.; Brunelli, L.; Papadatou, M.; Palatinus, A.; Grego, M.; Deprez, T. Macrodebris and microplastics from beaches in Slovenia. Mar. Pollut. Bull. 2014, 89, 356-366. [CrossRef]

56. Cózar, A.; Sanz-Martín, M.; Martí, E.; González-Gordillo, J.I.; Ubeda, B.; Ágálvez, J.; Irigoien, X.; Duarte, C.M. Plastic accumulation in the mediterranean sea. PLoS ONE 2015, 10, e0121762. [CrossRef]

57. Faure, F.; Saini, C.; Potter, G.; Galgani, F.; de Alencastro, L.; Hagmann, P. An evaluation of surface micro- and mesoplastic pollution in pelagic ecosystems of the Western Mediterranean Sea. Environ. Sci. Pollut. Res. 2015, 22, 12190-12197. [CrossRef]

58. Battisti, C.; Kroha, S.; Kozhuharova, E.; De Michelis, S.; Fanelli, G.; Poeta, G.; Pietrelli, L.; Cerfolli, F. Fishing lines and fish hooks as neglected marine litter: First data on chemical composition, densities, and biological entrapment from a Mediterranean beach. Environ. Sci. Pollut. Res. 2019, 26, 1000. [CrossRef]

59. Alomar, C.; Estarellas, F.; Deudero, S. Microplastics in the Mediterranean Sea deposition in coastal shallow sediments, spatial variation and preferential grain size. Mar. Environ. Res. 2016, 115, 1-10. [CrossRef]

60. Munari, C.; Corbau, C.; Simeoni, U.; Mistri, M. Marine litter on Mediterranean shores: Analysis of composition, spatial distribution and sources in north-western Adriatic beaches. Waste Manag. 2016, 49, 483-490. [CrossRef]

61. Suaria, G.; Avio, C.G.; Mineo, A.; Lattin, G.L.; Magaldi, M.G.; Belmonte, G.; Moore, C.J.; Regoli, F.; Aliani, S. The Mediterranean Plastic Soup: Synthetic polymers in Mediterranean surface waters. Sci. Rep. 2016, 6, 37551. [CrossRef] [PubMed]

62. Blăsković, A.; Fastelli, P.; Čižmek, H.; Guerranti, C.; Renzi, M. Plastic litter in sediments from the Croatian marine protected area of the natural park of Telaščica bay(Adriatic Sea). Mar. Pollut. Bull. 2017, 114, 583-586. [CrossRef] [PubMed]

63. Guerranti, C.; Cannasa, S.; Scopetani, C.; Fastelli, P. Plastic litter in aquatic environments of Maremma Regional Park (Tyrrhenian Sea, Italy): Contribution by the Ombrone river and levels in marine sediments. Mar. Pollut. Bull. 2017, 117. [CrossRef]

64. Vlachogianni, T.; Anastasopoulou, A.; Fortibuoni, T.; Ronchi, F.; Zeri, C. Marine litter assessment in the Adriatic and Ionian seas. IPA Adriat. DeFishGear Proj. 2017, 168, 70.

65. Vlachogianni, T.; Fortibuoni, T.; Ronchi, F.; Zeri, C.; Mazziotti, C.; Tutman, P.; Varezić, D.B.; Palatinus, A.; Trdan, Š.; Peterlin, M.; et al. Marine litter on the beaches of the Adriatic and Ionian Seas: An assessment of their abundance, composition and sources. Mar. Pollut. Bull. 2018, 131, 745-756. [CrossRef]

66. Poeta, G.; Conti, L.; Malavasi, M.; Battisti, C.; Acosta, A.T. R, Beach litter occurrence in sandy littorals: The potential role of urban areas, rivers and beach users in central Italy. Estuar. Coast. Shelf Sci. 2016, 181, 231-237. [CrossRef]

67. Ballerini, T.; Le Pen, J.-R.; Andrady, A.; Cole, M.; Galgani, F.; Kedzierski, M.; Pedrotti, M.-L.; Ter Halle, A.; Van Arkel, K.; Zettler, E.; et al. Plastic pollution in the ocean: What we know and what we don't know about. Technical Report. Plast. Ocean Platf. 2018. [CrossRef]

68. Giovacchini, A.; Merlino, S.; Locritani, M.; Stroobant, M. Spatial distribution of marine litter along italian coastal areas in the Pelagos sanctuary (Ligurian Sea-NW Mediterranean Sea): A focus on natural and urban beaches. Mar. Pollut. Bull. 2018, 130, 140-152. [CrossRef]

69. Merlino, S.; Abbate, M.; Pietrelli, L.; Canepa, P.; Varella, P. Marine litter detection and correlation with the seabird nest content. Rend. Lincei Sci. Fis. Nat. 2018, 29, 867-875. [CrossRef]

70. Galgani, F.; Claro, F.; Depledge, M.; Fossi, C. Monitoring the impact of litter in large vertebrates in the Mediterranean Sea within the European Marine Strategy Framework Directive (MSFD): Constraints, specificities and recommendations. Mar. Environ. Res. 2014, 100, 3-9. [CrossRef] 
71. Fossi, M.C.; Panti, C.; Guerranti, C.; Coppola, D.; Giannetti, M.; Marsili, L.; Minutoli, R. Are baleen whales exposed to the threat of microplastics? A case study of the Mediterranean fin whale (Balaenoptera physalus). Mar. Pollut. Bull. 2012, 64, 2374-2379. [CrossRef] [PubMed]

72. Fossi, M.C.; Coppola, D.; Baini, M.; Giannetti, M.; Guerranti, C.; Marsili, L.; Panti, C.; de Sabata, E.; Clò, S. Large filter feeding marine organisms as indicators of microplastic in the pelagic environment: The case studies of the Mediterranean basking shark (Cetorhinus maximus) and fin whale (Balaenoptera physalus). Mar. Environ. Res. 2014, 100, 17-24. [CrossRef] [PubMed]

73. Notarbartolo-di-Sciara, G.; Agardy, T.; Hyrenbach, D.; Scovazzi, T.; Van Klaveren, P. The Pelagos Sanctuary for Mediterranean marine mammals. Acquat. Conserv. 2009, 18, 367-391. [CrossRef]

74. Campanale, C.; Suaria, G.; Bagnuolo, G.; Baini, M.; Galli, M.; de Rysky, E.; Ballini, M.; Aliani, S.; Fossi, C.; Uricchio, V.F. Visual observations of floating macro litter around Italy (Mediterranean Sea). Mediterr. Mar. Sci. 2019, 20, 271-281. [CrossRef]

75. Browne, M.A.; Crump, P.; Niven, S.J.; Teuten, E.; Tonkin, A.; Galloway, T.; Thompson, R. Accumulation of microplastic on shorelines woldwide: Sources and sinks. Environ. Sci. Technol. 2011, 45, 9175-9179. [CrossRef]

76. Frère, L.; Paul-Pont, I.; Moreau, J.; Soudant, P.; Lambert, C.; Huvet, A.; Rinnert, E. A semi-automated Raman micro-spectroscopy method for morphological and chemical characterizations of microplastic litter. Mar. Pollut. Bull. 2016, 113, 461-468. [CrossRef]

77. Lippiat, S.; Opfer, S.; Courtney, A. Marine Debris Monitoring and Assessment: Recommendations for Monitoring Debris Trends in the Marine Environment; NOAA Technical Memorandum NOS-OR\&R-46; NOAA: Silver Spring, MD, USA, 2013.

78. Frias, J.; Pagter, E.; Nash, R.; O’Connor, I.; Carretero, O.; Filgueiras, A.; Viñas, L.; Gago, J.; Antunes, J.; Bessa, F.; et al. Standardised protocol for monitoring microplastics in sediments. JPI Ocean. BASEMAN Proj. Tech. Rep. 2018. [CrossRef]

79. Prata, J.C.; da Costa, J.P.; Duarte, A.C.; Rocha-Santos, T. Methods for sampling and detection of microplastics in water and sediment: A critical review. TrAC Trends Anal. Chem. 2019, 110, 150-159. [CrossRef]

80. Merlino, S.; Paterni, M.; Berton, A.; Massetti, L. Unmanned Aerial Vehicles for Debris Survey in Coastal Areas: Long-Term Monitoring Programme to Study Spatial and Temporal Accumulation of the Dynamics of Beached Marine Litter. Remote Sens. 2020, 12, 1260. [CrossRef]

81. Karkanorachaki, K.; Kiparissis, S.; Kalogerakis, G.C.; Yiantzi, E.; Psillakis, E.; Kalogerakis, N. Plastic pellets, meso-and microplastics on the coastline of Northern Crete: Distribution and organic pollution. Mar. Pollut. Bull. 2018, 133, 578-589. [CrossRef]

82. Nuelle, M.T.; Dekiff, J.H.; Remy, D.; Fries, E. A new analytical approach for monitoring microplastics in marine sediments. Environ. Pollut. 2014, 184, 161-169. [CrossRef]

83. Araujo, C.F.; Nolasco, M.M.; Ribeiro, A.M.P.; Ribeiro-Claro, P.J.A. Identification of microplastics using Raman spectroscopy: Latest developments and future prospects. Water Res. 2018, 142, 426-440. [CrossRef]

84. Ballent, A.; Corcoran, P.L.; Madden, O.; Helm, P.A.; Longstaffe, F.J. Sources and sinks of microplastics in Canadian Lake Ontario nearshore, tributary and beach sediments. Mar. Pollut. Bull. 2016, 110, 383-395. [CrossRef]

85. Clunies-Ross, P.J.; Smith, G.P.S.; Gordon, K.C.; Gaw, S. Synthetic shorelines in New Zealand? Quantification and characterisation of microplastic pollution on Canterbury's coastlines. N. Z. J. Mar. Freshw. Res. 2016, 50, 317-325. [CrossRef]

86. Di, M.; Wang, J. Microplastics in surface waters and sediments of the Three Gorges Reservoir, China. Sci. Total Environ. 2018, 616-617, 1620-1627. [CrossRef]

87. Elert, A.M.; Becker, R.; Duemichen, E.; Eisentraut, P.; Falkenhagen, J.; Sturm, H.; Braun, U. Comparison of different methods for MP detection: What can we learn from them, and why asking the right question before measurements matters? Environ. Pollut. 2017, 231, 1256-1264. [CrossRef]

88. Erni-Cassola, G.; Gibson, M.I.; Thompson, R.C.; Christie-Oleza, J.A. Lost, but Found with Nile Red: A Novel Method for Detecting and Quantifying Small Microplastics (1 $\mathrm{mm}$ to $20 \mu \mathrm{m}$ ) in Environmental Samples. Environ. Sci. Technol. 2017, 51, 13641-13648. [CrossRef]

89. Fischer, D.; Kaeppler, A.; Eichhorn, K.J. Identification of microplastics in the marine environment by Raman microspectroscopy and imaging. Am. Lab. 2015. Available online: 
https://www.americanlaboratory.com/914-Application-Notes/173574-Identifi-cation-of-Microplastics-inthe-Marine-Environment-by-Raman-Microspectroscopy-and-Imaging/ (accessed on 29 November 2020).

90. Horton, A.A.; Walton, A.; Spurgeon, D.J.; Lahive, E.; Svendsen, C. Microplastics in freshwater and terrestrial environments: Evaluating the current understanding to identify the knowledge gaps and future research priorities. Sci. Total Environ. 2017, 586, 127-141. [CrossRef]

91. Imhof, H.K.; Ivleva, N.P.; Schmid, J.; Niessner, R.; Laforsch, C. Contamination of beach sediments of a subalpine lake with microplastic particles. Curr. Biol. 2013, 23, 867-868. [CrossRef]

92. Karlsson, T.M.; Vethaak, A.D.; Almroth, B.C.; Ariese, F.; van Velzen, M.; Hassellöv, M.; Leslie, H.A. Screening for microplastics in sediment, water, marine invertebrates and fish: Method development and microplastic accumulation. Mar. Pollut. Bull. 2017, 122, 403-408. [CrossRef]

93. Lots, F.A.E.; Behrens, P.; Vijver, M.G.; Horton, A.A.; Bosker, T. A large-scale investigation of microplastic contamination: Abundance and characteristics of microplastics in European beach sediment. Mar. Pollut. Bull. 2017, 123, 219-226. [CrossRef]

94. Maes, T.; Jessop, R.; Wellner, N.; Haupt, K.; Mayes, A.G. A rapid-screening approach to detect and quantify microplastics based on fluorescent tagging with Nile Red. Sci. Rep. 2017, 7, 44501. [CrossRef] [PubMed]

95. Scheurer, M.; Bigalke, M. Microplastics in Swiss Floodplain Soils. Environ. Sci. Technol. 2018, 52, 3591-3598. [CrossRef]

96. Shan, J.; Zhao, J.; Liu, L.; Zhang, Y.; Wang, X.; Wu, F. A novel way to rapidly monitor microplastics in soil by hyperspectral imaging technology and chemometrics. Environ. Pollut. 2018, 238, 121-129. [CrossRef]

97. Sruthy, S.; Ramasamy, E.V. Microplastic pollution in Vembanad Lake, Kerala, India: The first report of microplastics in lake and estuarine sediments in India. Environ. Pollut. 2017, 222, 315-322. [CrossRef]

98. Van Cauwenberghe, L.; Devriese, L.; Galgani, F.; Robbens, J.; Janssen, C.R. Microplastics in sediments: A review of techniques, occurrence and effects. Mar. Environ. Res. 2015, 111, 5-17. [CrossRef]

99. Xiong, X.; Zhang, K.; Chen, X.; Shi, H.; Luo, Z.; Wu, C. Sources and distribution of microplastics in China's largest inland lake-Qinghai Lake. Environ. Pollut. 2018, 235, 899-906. [CrossRef]

100. Young, A.; Elliott, J.A. Characterization of microplastic and mesoplastic debris in sediments from Kamilo Beach and Kahuku Beach, Hawai'i Risk of Zoonotic Disease from a Wildlife Reservoir View project. Mar. Pollut. Bull. 2016, 113, 477-482. [CrossRef]

101. Zada, L.; Leslie, H.A.; Vethaak, A.D.; Tinnevelt, G.H.; Jansen, J.J.; de Boer, J.F.; Ariese, F. Fast microplastics identification with stimulated Raman scattering microscopy. J. Raman Spectrosc. 2018, 49, 1136-1144. [CrossRef]

102. Endo, S.; Takizawa, R.; Okuda, K.; Takada, H.; Chibab, K.; Kanehiro, H.; Ogi, H.; Yamashita, R.; Date, T. Concentration of PCB in beached resin pellets: Variability amond individual particles and regional differences. Mar. Pollut. Bull. 2005, 58, 1103-1114. [CrossRef]

103. Ogata, Y.; Takada, H.; Mizukawa, K.; Hirai, H.; Iwasa, S.; Endo, S.; Mato, Y.; Saha, M.; Okuda, K.; Nakashima, A.; et al. International Pellet Watch: Global monitoring of persistent organic pollutants (POPs) in coastal waters. 1. Initial phase data on PCBs, DDTs, and HCHs. Mar. Pollut. Bull. 2009, 58, 1437-1446. [CrossRef]

104. Karapanagioti, H.K.; Ogata, Y.; Takada, K. Eroded plastic pellets as monitoring tools for polycyclic aromatic hydrocarbons (PAH):Laboratory and field studies. Glob. Nest J. 2010, 12, 327-334.

105. Rochman, C.M.; Eunha, H.; Hentschel, B.T.; Kaye, S. Long-Term Field Measurement of Sorption of Organic Contaminants to Five Types of Plastic Pellets: Implications for Plastic Marine Debris. Environ. Sci. Technol. 2014, 47, 1646-1654. [CrossRef]

106. Fanini, L.; Bozzeta, F. Dynamics of plastic resin pellets deposition on a microtidal sandy beach: Informative variables and potential integration into sandy beach studies. Ecol. Indic. 2018, 89, 309-316. [CrossRef]

107. Halden, R.U. Risks, Plastics and Health. Annu. Rev. Public Health 2010, 31, 179-194. [CrossRef]

108. Murray, C.P. Plastic contamination in the decapod crustacean Nephrops norvegicus. Mar. Pollut. Bull. 2011, 62, 1207-1217. [CrossRef]

109. Engler, R.E. The complex interaction between marine debris and toxic chemicals in the ocean. Environ. Sci. Technol. 2012, 62, 12302-12345. [CrossRef]

110. Shaw, D.G.; Day, R.H. Colour- and form-dependent loss of plastic micro-debris from the North Pacific Ocean. Mar. Pollut. Bull. 1994, 28, 38-42. [CrossRef] 
111. Acampora, H.; Schuyler, Q.A.; Townsend, K.A.; Hardesty, B.D. Comparing plastic ingestion in juvenile and adult stranded short-tailed shearwaters (Puffinus tenuirostris) in eastern Australia. Mar. Pollut. Bull. 2014, 78, 63-68. [CrossRef]

112. Kataoka, T.; Hinata, H. Evaluation of beach cleanup effects using linear system analysis. Mar. Pollut. Bull. 2015, 91, 73-81. [CrossRef]

113. Antunes, J.C.; Frias, J.G.L.; Micaelo, A.C.; Sobral, P. Resin pellets from beaches of the Portuguese coast and adsorbed persistent organic pollutants. Estuar. Coast. Shelf Sci. 2013, 130, 62-69. [CrossRef]

114. Antunes, J.; Frias, J.; Sobral, P. Microplastics on the Portguese coast. Mar. Pollut. Bull. 2018, 131, $294-302$. [CrossRef]

115. Sciascia, R.; Magaldi, M.; Vetrano, A. Current reversal and associated variability within the Corsica Channel: The 2004 case study, Deep Sea Research Part I. Oceanogr. Res. Pap. 2019, 144, 39-51. [CrossRef]

116. Fossi, M.C.; Romeo, T.; Baini, M.; Panti, C.; Marsili, L.; Campani, T.; Canese, S.; Galgani, F.; Druon, J.N.; Airoldi, S.; et al. Plastic debris occurrence, convergence areas and fin whales feeding ground in the mediterranean marine protected area pelagos sanctuary: A modeling approach. Front. Mar. Sci. 2017, 4, 167. [CrossRef]

117. Borrione, I.; Falchetti, S.; Alvarez, A. Physical and dynamical characteristics of a $300 \mathrm{~m}$-deep anticyclonic eddy in the Ligurian Sea (Northwest Mediterranean Sea): Evidence from a multi-platform sampling strategy. Deep Sea Res. Part I Oceanogr. Res. Pap. 2019, 116, 145-164. [CrossRef]

118. Cipriani, L.E.; Perfetti, A.; Pranzini, E.; Vitale, G. Azioni di tutela delle dune costiere del Parco Regionale Migliarino San Rossore Massaciuccoli (Toscana settentrionale). Studi Costieri 2010, 17, 165-179.

119. Xiong, X.; Tua, Y.; Chena, X.; Jiangb, X.; Shic, H.; Wu, C.; Elser, J.J. Ingestion and egestion of polyethylene microplastics by goldfish (Carassius auratus): Influence of color and morphological features. Heliyon 2019, 5, e03063. [CrossRef]

120. Miranda, D.; Freire De Carvalho-Souza, G. Are we eating plastic-ingesting fish? Mar. Pollut. Bull. 2016, 103, 109-114. [CrossRef]

121. Karthik, R.; Robin, R.S.; Purvaja, R.; Ganguly, D.; Anandavelu, I.; Raghuraman, R.; Hariharan, G.; Ramakrishna, A.; Ramesh, R. Microplastics along the beaches of southeast coast of India. Sci. Total Environ. 2018, 645, 1388-1399. [CrossRef]

122. Vaskova, H. A powerful tool for material identification: Raman spectroscopy. Int. J. Math. Models Methods Appl. Sci. 2011, 5, 1205-1212.

123. González-García, D.; Bersani, D.; Dingwell, D.B.; Del Negro, C. Raman Spectroscopy from Laboratory and Proximal to Remote Sensing: A Tool for the Volcanological Sciences. Remote Sens. 2020, 12, 805.

124. Rochman, C.M.; Cook, A.M.; Koelmans, A. Plastic debris and policy: Using current scientific understanding to invoke positive change. Environ. Toxicol. Chem. 2016, 35, 1617-1626. [CrossRef]

Publisher's Note: MDPI stays neutral with regard to jurisdictional claims in published maps and institutional affiliations.

(C) 2020 by the authors. Licensee MDPI, Basel, Switzerland. This article is an open access article distributed under the terms and conditions of the Creative Commons Attribution (CC BY) license (http://creativecommons.org/licenses/by/4.0/). 